Arnett, Nathan, \& Wagers, Matthew. (2017). Subject encodings \& retrieval interference.

Journal of Memory and Language, 93, 22-54.

http://dx.doi.org/10.1016/j.jml.2016.07.005

\title{
Introduction
}

Incremental sentence comprehension requires integrating incoming input into a structured representation while establishing dependencies between elements in a way that conforms to grammatical constraints. Given that dependents may be separated by large amounts of interpolated material, both processes require a means of bringing current input into contact with the partially-interpreted structures stored in memory. This study is concerned with questions about what is encoded, and how it is retrieved.

Subject-verb dependencies have provided a useful context for examining the retrieval mechanism used to re-access constituent encodings in the comprehension of grammatical dependencies. Van Dyke \& Lewis (2003) compared sentences like those in (1), manipulating similarity between the target matrix subject and the embedded subject of the relative clause. They found that the subject-verb dependency is more difficult when the grammatical subject is complex, and contains additional subjects (1b). This difficulty is reflected in both increased reading times at the matrix verb region, e.g. was standing, as well as offline comprehension questions and grammaticality judgments.

(1) The student who...

a. $t$ was waiting for the exam

b. thought that the exam was important ... was standing in the hallway.

Van Dyke \& Lewis (2003) attribute the comparative difficulty to structural similarity between the two (underlined) subject encodings (Anderson \& Neely, 1996; Gordon, Hendrick \& Johnson, 2001). Van Dyke \& Lewis (2003) argued that the subject must be retrieved at the verb, and the similarity between potential subjects leads to difficulty in discriminating the correct subject.

Difficulty stemming from similarity between target encodings and grammatically inappropriate constituents has been found in a diverse array of constructions using a variety of methodologies, and both online and offline measures. These studies have identified a number of factors that affect the speed and accuracy of comprehension processes, including morphosyntactic and semantic properties like case and agreement 
features, referential status, and the distance between dependents (Van Dyke \& Lewis, 2003; Van Dyke, 2007; Wagers, Lau \& Phillips, 2009; Fedorenko, Babyonyshev \& Gibson, 2004; Gordon et al., 2001; McElree, Foraker \& Dyer, 2003).

The common thread in these studies is that memory access during sentence processing is mediated by a content-addressable retrieval mechanism, where the inherent properties of encodings serve as 'cues' to identify target memories. These cues have been assumed to be, among other things, grammatical features, such as PLURAL. When matched against the contents of memory, these cues provide parallel access to information in encodings matching the retrieval cues, and diminish the need for a slow, serial search (McElree et al., 2003). However, this content-addressability gives rise to similarity-based interference effects when the retrieval cues cannot unambiguously identify a single encoding ("cue-overload"; Nairne, 2006). Thus, in (1) the verb triggers retrieval of the subject via the retrieval cues, and when matched against the contents of memory, these cues identify two encodings in (1b), the student and the exam. The relative difficulty of (1b) over (1a) reflects similarity between the subject constituents and the retrieval cues at the verb, which Van Dyke \& Lewis (2003) capture with the feature "[+SUBJECT]".

What are the dimensions of similarity that lead constituents to interfere? We address this question by examining whether "[+SUBJECT]" is best characterized as shorthand for a collection of morphosyntactic properties associated with the structural subject position (Chomsky, 1981; see McCloskey, 1997, for a review) or a primitive grammatical feature, as in theories taking subjecthood to be determined by the most prominent element on an argument-structure representation (Pollard \& Sag, 1994; Bresnan, 1982, inter alia). The distinction is important, since these cues relate encodings on potentially quite distinct levels of representation: phrase-structure and argumentstructure. The materials used in previous studies do not directly address these possibilities, since all elements considered to be potentially interfering are external arguments occupying the highest structural subject position (Van Dyke \& Lewis, 2003; Van Dyke, 2007).

Furthermore, studies seeking to manipulate similarity within complex subjects generally correlate the presence of the embedded subject with the number of clauses, i.e. 
the additional clause introduced as the complement of thought in (1b). This is problematic because the degree of clausal embedding has been shown to correlate with performance on sentence memory tasks, as well as an array of working memory tasks (Roberts \& Gibson, 2002). Furthermore, previous studies attempting to eliminate this issue have found reduced interference effects in online measures (Wagers, 2008).

The current study examines the nature of information used to identify subject encodings by probing whether argument- or phrase- structural notions provide a better account of the interference effects from grammatically inappropriate subjects. Data from three experiments using both online and offline measures support the view that the retrieval cues characterize subjects structurally, in terms of their syntactic properties. Functionally, the relevant dimension of similarity in these experiments is 'subject of a finite clause'. Overall the findings support the view that difficulties in subject-verb attachment reflect similarity-based interference stemming from cue-based retrieval.

\section{Interference effects}

Within language processing, interference effects have been hypothesized to explain processing asymmetries between subject- and object- relatives (Gordon et al., 2001; Gordon, Hendrick \& Johnson, 2004; Gordon, Hendrick, Johnson \& Lee, 2006), agreement attraction (Wagers et al., 2009), spurious licensing of negative polarity items (Drenhaus, Saddy \& Frisch, 2005; Vasishth, Brüssow, Lewis \& Drenhaus, 2008), locality effects (Vasishth \& Lewis, 2006), and subject-verb attachment (Van Dyke \& Lewis, 2003; Van Dyke, 2007; Van Dyke \& McElree, 2011). Interference has also been proposed as an explanation for difficulties in center-embedding constructions (Lewis, 1996; Lewis \& Vasishth, 2005).

For example, Van Dyke \& McElree (2006) compared object-cleft sentences using a memory-load paradigm (Gordon et al., 2001) in a $2 \times 2$ design crossing structures like those in (3-4) with a memorization task. In the memory load conditions, participants memorized a list of nouns prior to the presentation of experimental sentences. The nouns were chosen such that the semantic fit between the memory elements and the gap site in the object cleft would be stronger in (3) over (4), i.e. the to-be-remembered items are fixable, but not sailable. 
(2) Memory list: table, sink, truck

(3) Non-interfering condition:

It was the boat that the guy who lived by the sea sailed _ in two sunny days.

(4) Interfering condition:

It was the boat that the guy who lived by the sea fixed _ in two sunny days.

The results of the Van Dyke \& McElree (2006) study provide clear evidence of interference effects in language processing, driven by overlapping retrieval cues. The interaction of memory load and the verb manipulation was significant in the reading times: at the verb there was a slowdown in the memory load/fixed conditions, as well as a general slowdown for the interference conditions in the following region. Van Dyke \& McElree concluded that retrieval of the clefted noun was impacted by other elements in memory that were not grammatical dependents of the verb, in particular those those that were compatible with the semantic features of the verb.

\section{Kinds of subjects}

We address questions about the precise character of retrieval cues by probing the nature of information used by a verb to identify its subject. More specifically, we measure processing difficulty at a verb - when the subject is retrieved, by hypothesis in structures such as that shown in (5). We manipulated similarity between the matrix subject and an embedded subject of a subject-attached relative clause that intervenes between the verb and the target subject.

(5) $\mathrm{NP}[\mathrm{cP}$ who $\mathrm{V}[\mathrm{cP}$ that $\mathrm{NP} \ldots]]$ verb...

In Experiment 1, we seek to disentangle structural and thematic notions of subjecthood, while replicating previous effects of interference from embedded subjects (Van Dyke \& Lewis, 2003; see also Van Dyke, 2007; Van Dyke \& McElree, 2011). We sharpen the issue of interference in complex subject attachment by probing whether a "[+SUBJECT]" retrieval cue is better viewed as targeting a phrase-structure representation or an argument-structure representation. The distinction is important, because not all subjects need occupy the same structural position. For example, if we compare a 
tensed clause (6) with an event/process nominalization (7), the underlined elements are similar in terms of their phrase-structure geometry and their thematic relations.

(6) The enemy destroyed the city.

(7) The enemy's destruction of the city.

(Chomsky, 1970)

Subject of a clause:

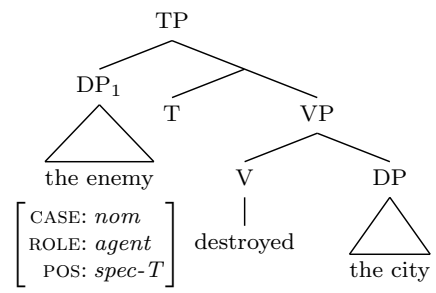

Subject of an event nominalization:

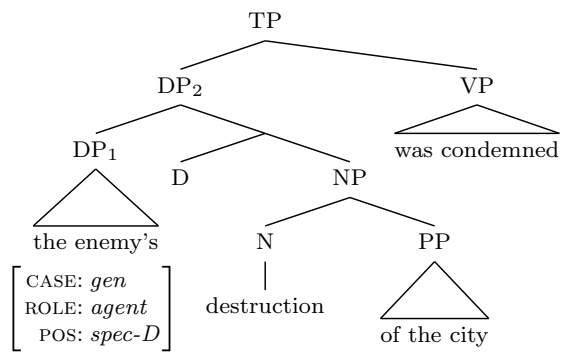

Figure 1: Syntactic structures of a clause (left) and an event nominalization (right). In both structures, the nominal expression the enemy is the most prominent element.

As shown in Figure 1, both elements are the most prominent constituent in their structural domain: they occupy the highest structural position ('specifier' position; Abney, 1987), and are thematically linked to the external/subject argument of the predicate (Grimshaw, 1990). They differ in their domain of occurrence - their specific structural position - and case. In English, the subject of a finite (tensed) clause is assigned NomInATIVE case, while possessors are assigned Genitive case. Thus, given these formal parallels, the possessor of an event nominalization can be viewed as a 'subject' of the nominal domain.

Consider now a sentence like that shown below in (8), where the matrix verb is separated from its subject by an intervening relative clause, which takes an event nominalization (bracketed) as embedded subject. This sentence contains three thematic subjects: hostess, chef, and preparation. In contrast, the same sentence contains only two structural (and nominative) subjects, namely hostess and preparation.

(8) The hostess who thought that [DP the chef's preparation of the blowfish ] delayed the guests was yelling in the kitchen. 
If retrieval of the subject at a verb is guided by thematic properties encoded in the argument structure of the verb, then sentences like those in (8) should be more difficult than otherwise identical sentences lacking the possessor. On the other hand, if the retrieval cues characterize subjects in terms of their syntactic properties, i.e. case or position, then the processing at the verb should be insensitive to the presence of the possessor, because it is not sufficiently 'subject-like'.

Note that this logic takes interference at the verb to depend on the number of subjects (two versus three). These predictions are consistent with the model of Lewis \& Vasishth (2005), where additional matching encodings increase interference by reducing the associative match between the retrieval cues and the target element. Furthermore, while distinguishing between thematic and structural subjects, the precise dimensions of syntactic (dis)similarity are not independently manipulated. In particular, the possessor is distinct from the target subject in terms of its case (GENITIVE versus NOMINATIVE, respectively) and in terms of its position (specifier of a nominal versus specifier of a clause). In Experiments 2-3, we examine the structural properties of subjects that can lead to interference.

One construction where the position and case of subject constituents come apart is that headed by so-called 'exceptional case-marking' (ECM) predicates like believe. Members of this class typically embed either a finite clause complement hosting a nominative subject (9a), or a non-finite/untensed complement taking an accusative subject (9b). Crucially, for our purposes, contemporary syntactic theory locates the embedded subject of either complement (underlined) in the structural subject position of the embedded clause (e.g. Chomsky, 1995, among others).

(9) a. Cecil believes [that she is lying.]

S-complement

b. Cecil believes [her to be lying.]

$E C M$

$$
\text { Cecil persuaded her [ PRO to lie.] }
$$

Object Control

The ECM sentences are also superficially similar to another class of verbs embedding a non-finite clause, namely Object Control verbs like (10). The verb persuade is emblematic of this class: like ECM structures, it takes a non-finite to-VERB complement whose subject must be interpreted as the accusative marked nominal expression. 
However, as the name implies, the meaning of the subject of the embedded clause in (10) is mediated by an interpretive dependency, 'Control', that holds between the matrix object and a null embedded subject, which we assume to be the null pronominal element 'PRO'. Thus, unlike (9b), the accusative nominal in (10) is the object of the matrix verb, persuade, similar in terms of case but distinct in syntactic position. One outcome of this difference is that the accusative NP of an Object Control predicate is thematic, and selected by the control verb, while the accusative element of ECM predicates is an argument of the embedded verb, and need not be thematic. To demonstrate, one outcome of these differences is that the embedded subject of a control predicate cannot be a dummy element like there which is prohibited from thematic positions, while such elements are perfectly natural in ECM sentences:

(11) a. Cecil believes there to be a solution to this problem.

b. * Cecil persuaded there to be a solution to this problem.

In summary, verbs like believe embed either a tensed clausal complement (S-comp) or a non-finite clausal complement (ECM). The subjects of these complements are similar in terms of their syntactic position, but differ in their case properties. ECM structures, in turn, are similar to Object Control structures in that they are followed by an accusative nominal expression, but differ in the syntactic position of this element: a subject for ECM, and an object for Object Control. These structures are schematized below:

(12) S-complement

Cecil believes [CP (that) [TP the monster NOM $_{\text {Tas... }]]}$

(13) $E C M$

Cecil believes [TP the monster $_{\mathrm{ACC}}$ to...]

(14) Object Control

Cecil persuaded the monster $_{\mathrm{ACC}}[\mathrm{CP}[\mathrm{TP}$ PRO to... ]]

In Experiments 2-3 we leverage these properties to examine the role of case and position in subject retrieval. As in previous studies, we examine the processing at the 
verb when its subject is complex, and contains an additional clause that itself contains a subject. An example structure is shown in (15).

(15) The explorer [cP who believed/persuaded the monster to... ] was insane...

If the cues at the verb characterize subjects by their specific structural position, then we expect sentences containing verbs of the believe-class to be more difficult than sentences where the embedded clause contains an Object Control verb, since only the former introduces an additional overt subject ${ }^{1}$. Importantly, though, S-comp and ECM sentences should pattern together, since the interveners occur in the same syntactic position. In contrast, if the subject retrieval cues target case properties, then we expect more difficulty at the verb for S-comp sentences compared to ECM or Object Control, since only the S-comp sentences contain an intervening subject that is similar to the target matrix subject-both are Nominative. Finally, inclusion of the object control structures allows us to test whether subject retrieval involves a combination of case and position cues. If the retrieval structure targets a nominative subject in SPEC-T, then the embedded subject will fully match the retrieval cues only in the S-complement sentences, while the ECM interveners will match only in position, not case. If both case and position cues are used, then, we expect a three-way distinction in difficulty at the verb: S-complement sentences should be the hardest (full match), object control sentences the easiest (no match), with ECM sentences in-between (partial match).

\footnotetext{
${ }^{1}$ An anonymous reviewer notes that this point is somewhat complicated by the presence of an implicit subject (PRO) in the Object Control sentences. The predictions here turn on assumptions about the grammatical properties of PRO. For instance, case-similarity between the matrix and implicit subjects depends on whether PRO is distinct in being a caseless element (Bouchard, 1984), bearing 'NULL' case (Chomsky \& Lasnik, 1993; Martin, 2001), or similar in taking structural nominative case (Landau, 2006). We return to this issue below. For the present purposes, we assume that the case borne by PRO is distinct from the case of an overt subject, and that only overt arguments interfere.
} 


\section{Experiment 1}

\section{Design $\mathcal{E}$ predictions}

Experiment 1 had two goals. One, to probe whether interference effects from grammatically inappropriate subjects reflects similarity to the target in terms of argumentstructure or phrase structure. Two, to extend previous findings of interference from embedded subjects to materials that control for depth of embedding.

We address these issues using sentences such as that shown in (16), by probing for interference at the matrix verb from an embedded subject that intervenes between a verb and its target subject, while manipulating similarity between the intervening subject and the (putative) retrieval cues provided by the verb. Thematic similarity between the matrix and embedded subjects is manipulated by comparing sentences such as (16) to variants without a possessor.

(16) The hostess who thought that the (chef's) careful preparation of the blowfish delayed the guest was yelling in the kitchen.

The possessor chef in (16) is thematically similar to the target matrix subject in that both are an external argument. They differ in their syntactic context-a nominal for the possessor, and a clause for the target subject—and their case: genitive or nominative, respectively. Thus, the sentence in (16) contains three thematic subjects, but only two structural subjects.

While the nominalization is required to make the possessor sufficiently 'subjectlike', it also increases the complexity of the intervening subject. There is evidence that increasing a constituent's complexity modulates difficulty in retrieval. Hofmeister (2011) found that increasing the complexity of a to-be-retrieved constituent facilitated processing at the integration site, so that processing at a verb was faster when its subject was complex, e.g. a communist versus an alleged Venezuelan communist, but complexity had no effect on processing at the intervening regions. In configurations like (16), the complex constituent is not the target of retrieval, and so increasing the complexity of the intervening subject may facilitate (mis)retrieval of the embedded subject, and lead to difficulty when the matrix subject is retrieved. 
In order to examine the role of intervener complexity on retrieval, Experiment 1 also compared sentences like (16), to sentences like (17), where the nominalization occurs object position. These sentences simply swapped the embedded subject and object, so that lexical items remained constant across conditions, modulo the possessor.

(17) The hostess who thought that the guest delayed the (chef's) careful preparation of the blowfish was yelling in the kitchen.

The additional word for the possessor might matter, either because it introduces an additional discourse referent, or because it increases overall similarity between constituents in (e.g.) category. While an overall cost for the possessor will be reflected as increased difficulty in possessor conditions, if the possessor engenders retrieval interference then the difficulty will not arise before the retrieval triggered by the critical verb.

The sentences in (16) and (17) all contain an embedded structural subject, either a nominalization or a simple Det+Noun constituent. In order to establish interference for the presence of an embedded subject, we also compared the sentences in (16-17), the 'interference conditions', to control sentences such as that shown in (18).

(18) The hostess who was fortunate to have delayed the careful preparation of the blowfish was yelling in the kitchen.

Control sentences used raising predicates, e.g. fortunate, to leave the embedded subject unexpressed, and co-referent to the matrix (target) subject. Our control sentences are analogous to the 'low interference' conditions of Van Dyke \& Lewis (2003) and Van Dyke (2007), but contained an additional clause (to have) to control for the number of clauses across experimental conditions. Otherwise, there were only minimal lexical differences between the control condition and the interference conditions. In particular, like the simple intervener sentences in (17), the control sentences contained a nominalization in object position. This was done to easily match lexical material, and guard against an overall cost for the additional complexity of the nominalization in the interference conditions. 
The resulting experimental design was $2 \times 2+1$, with factors for the presence of a possessor (yes/no), the position of the complex nominalization constituent (subject or object) plus the control condition. For all experimental sentences, the critical regions are the matrix verbs, e.g. was yelling, where the verb is integrated with the matrix subject.

The predictions are as follows. If embedded lexical subjects engender interference, then the interference conditions will be more difficult than the control conditions, reflected as either a slowdown at the critical regions or reduced comprehension accuracy. Predictions about the source of interference depend on comparisons within the interference conditions. If the verb uses a thematic cue like [+EXTERNAL-ARG] to identify the target subject, then similarity between the possessor and target matrix subject will engender interference at the verb, and sentences with a possessor will be more difficult than sentences without a possessor. On the other hand, if the verb's cues target syntactic subjects, using a case cue like [CASE:NOMINATIVE] or a position cue like [POSITION:SPEC-T], then we expect no effect of the possessor. Finally, if complexity affects constituent retrieval, then we expect greater difficulty at the verb for sentences with a nominalization in subject position only, due to structural similarity between the complex nominalization and the target matrix subject.

\section{Participants}

Forty native speakers of English from the University of California, Santa Cruz community participated in the experiment. All participants provided informed consent. Compensation for participation in the experiment was $\$ 15$.

\section{Materials}

Sample materials for Experiment 1 are shown in Table 1. The full materials for all experiments are provided in Appendix A. Experimental materials consisted of 30 item sets arranged in a $2 \times 2+1$ factorial design that crossed the presence of a possessor (yes/no) with the complexity of the intervening subject (complex nominalization/simple DP). 
All experimental sentences began with a 1-2 word adverbial phrase, e.g. Somewhat surprisingly, to eliminate a potential primacy effect for the target subject occurring trial-initially. Following this phrase, the first five words of each experimental item were of the form: det-N-who-V-that. The noun is the target subject, and the verb always embedded a clausal complement of the form $D P_{1}-V-D P_{2}$. In complex intervener conditions, the embedded subject $\mathrm{DP}_{1}$ was an event nominalization and the embedded object $\mathrm{DP}_{2}$ was a simple Det-Noun sequence. Simple intervener conditions reversed the order of these arguments, with a det-noun nominal as the embedded subject and the nominalization the embedded object. Modulo the possessor, the four experimental conditions were controlled to contain the same lexical material. The structure of the nominalization was always of the form the-(Poss)-Adj-Nominalization-PP. The nominalization always contained a subject-oriented adjective like deliberate to force a reading in which the noun had an eventive argument structure and the possessor is unambiguously thematic (Grimshaw, 1990). The 30 sets of five conditions were distributed across five

\section{Condition SAmple SENTENCE}

\section{Complex intervener conditions}

Posses- $\quad$ The hostess who thought that the chef's careful preparation of the blowfish delayed the server was yellir sor

No Pos- The hostess who thought that the careful preparation of the blowfish delayed the server was yellir sessor

\section{Simple intervener conditions}

Posses- The hostess who thought that the server delayed the chef's careful preparation of the blowfish was yellir sor

No Pos- The hostess who thought that the server delayed the careful preparation of the blowfish was yellir sessor

Control The hostess who was fortunate to have delayed the chef's careful preparation of the blowfish was yellin

Table 1: Sample set of experimental materials for Experiment 1. Not shown: Initial adverbial phrase and sentence-final prepositional phrase. 
lists in a Latin Square design, and combined with 114 filler sentences.

Filler sentences were designed to be of similar length to experimental sentences. 48 fillers were from an unrelated experiment on the comprehension of wh-dependencies. All sentences were grammatical. In order to discourage participants from using the presence of a relative-clause modifier to identify experimental sentences, one third of fillers contained an argument modified by a relative clause. The remaining sentences contained a variety of syntactic constructions, but all fillers were multi-clausal structures to mask the experimental sentences in terms of their complexity and depth of embedding.

Each trial was followed by a comprehension question. These were designed to probe comprehension of the subject-verb relation in the matrix and embedded clauses. A third question type probed the interpretation of the sentence-final verb-PP modifier, to serve as a baseline for measures of interference in comprehension accuracy. Negative versions of each comprehension question were created by substituting the correct matrix/embedded subject with the subject of the embedded/matrix clause, respectively. This avoids participants answering based on a simple recognition judgement of whether the subject noun occurred in the sentence or not.

\section{Procedure}

Sentences were presented on an Apple desktop computer using the Linger software (Doug Rohde, MIT) in a self-paced word-by-word moving window paradigm (Just, Carpenter \& Woolley, 1982). After each sentence, a yes/no comprehension question was presented in its entirety. Participants were instructed to read each sentence at a natural pace, and to answer each question as accurately as possible. Participants advanced through the sentence by pressing the space-bar, resting their hand on the home keys, and responded to yes/no questions by pressing the ' $\mathrm{f}$ ' and ' $\mathrm{j}$ ' keys, respectively. Feedback was provided for incorrect responses only. Order of presentation was pseudorandomized for each participant in a Latin square design. Each experimental session began with six practice trials. 
Analysis

Data and analysis scripts for all experiments are available from the first author's website. Experimental data was analyzed in the R programming environment for statistical computing (R Core Team, 2013), and modeled in a series of linear mixed-effects models using the lmer4 package (Bates, Maechler, Bolker \& Walker, 2013). Prior to analyzing the reading times, extreme observations less than $50 \mathrm{~ms}$ and greater than $3000 \mathrm{~ms}$ were removed. This exclusion affected $.002 \%$ of the data. Six participants were removed for extremely low accuracy $(<65 \%)$. RTs were analyzed in regions consisting of a single word and aligned prior to analysis, as in (19).

(19) Experiment 1 analysis regions:

Target the hostess $_{2}$

Embedding $V \quad$ who $_{3}$ thought $_{4}$ that $_{5}$

Intervener (complex) the ${ }_{6}$ chef's careful preparation 9 of the blowfish

(simple) the ${ }_{6}$ guest $_{9}$

Embedded VP (complex interveners) delayed ${ }_{13}$ the $_{14}$ guest $_{17}$

(simple interveners) delayed ${ }_{13}$ the $_{14}$ chef's careful preparation ${ }_{17}$ of the blowfish

Critical was $_{21}$ yelling 22

Spillover $\quad$ in $_{23}$ the $_{24}$ kitchen $_{25}$

While the ordinal position of the critical region in all conditions varied by only one word (due to the possessor), the embedded verb occurred earlier in simple intervener and control conditions than complex intervener conditions. In order to correct for these differences, and correct for differences in participants' reading rates, statistical analysis of reading times was performed on the residual reading times. This correction has been advocated by Ferreira \& Clifton (1986) in order to control for the effect of character length on reading times (Rayner, 1977; Rayner, Sereno \& Raney, 1996), while more recently a growing number of researchers have used this method to control for this and other confounding factors (e.g. Van Dyke \& Lewis, 2003; Hofmeister, 2011; Jaeger, Fedorenko \& Gibson, 2010). In addition to facilitating comparisons to previous 
studies, residual reading times have the advantage of allowing results to be reported on a natural scale, namely milliseconds. Residual reading times were computed by first fitting a first-order linear regression equation to the filler sentence reading times for each subject, with predictors for word-length in characters, the position of the trial sentence in the materials list, and the position of the word within the sentence. Since the effect of word-position is non-linear, reflecting differences in reading rates, we used the log of word-position (which improved model fit relative to an untransformed predictor). For each participant, the model from filler data was used to predict the RTs for experimental sentences as a function of word-length, trial position, and word position. The residuals of this model were then used as the dependent variable in the reported statistical models.

Outliers were removed by first computing z-scores of residual RTs by region and condition, then removing observations whose absolute z-score exceeded |3| (Grodner \& Gibson, 2005). This criteria excluded $1.21 \%$ of the data. Residual RTs at each region were analyzed in a series of linear mixed-effects models with fixed-effects for experimental factors. For comparisons within the interference conditions, experimental factors were modeled using deviation coding $(.5,-.5)$, with complex intervening subjects and POss:Yes as the positive coefficients. Comparisons between interference conditions and the control condition were analyzed in a separate maximal model, which used treatment coding $(0,1)$ with the control condition as the reference level, so that coefficients reflect by-condition differences from the control mean. All models follow the recommendations of Barr, Levy, Scheepers \& Tily (2013) in using the maximal random-effects structure (experimental factors nested under participants and items; see also Baayen, Davidson \& Bates, 2008). When the maximal model would not converge, a step-wise, backwards procedure was used: inspecting the model and dropping the random effect term associated with the lowest variance. The significance of experimental coefficients was evaluated by interpreting the $t$-score of the coefficient as a z-score, with significant coefficients those whose $t / z$ exceeded 2 (Gelman \& Hill, 2007; Levy, Fedorenko \& Gibson, 2013; see Baayen et al., 2008, for justification).

Comprehension accuracy data was analyzed in a series of logistic regression models (Jaeger, 2008), using the same contrast coding described above for the RT analysis. 


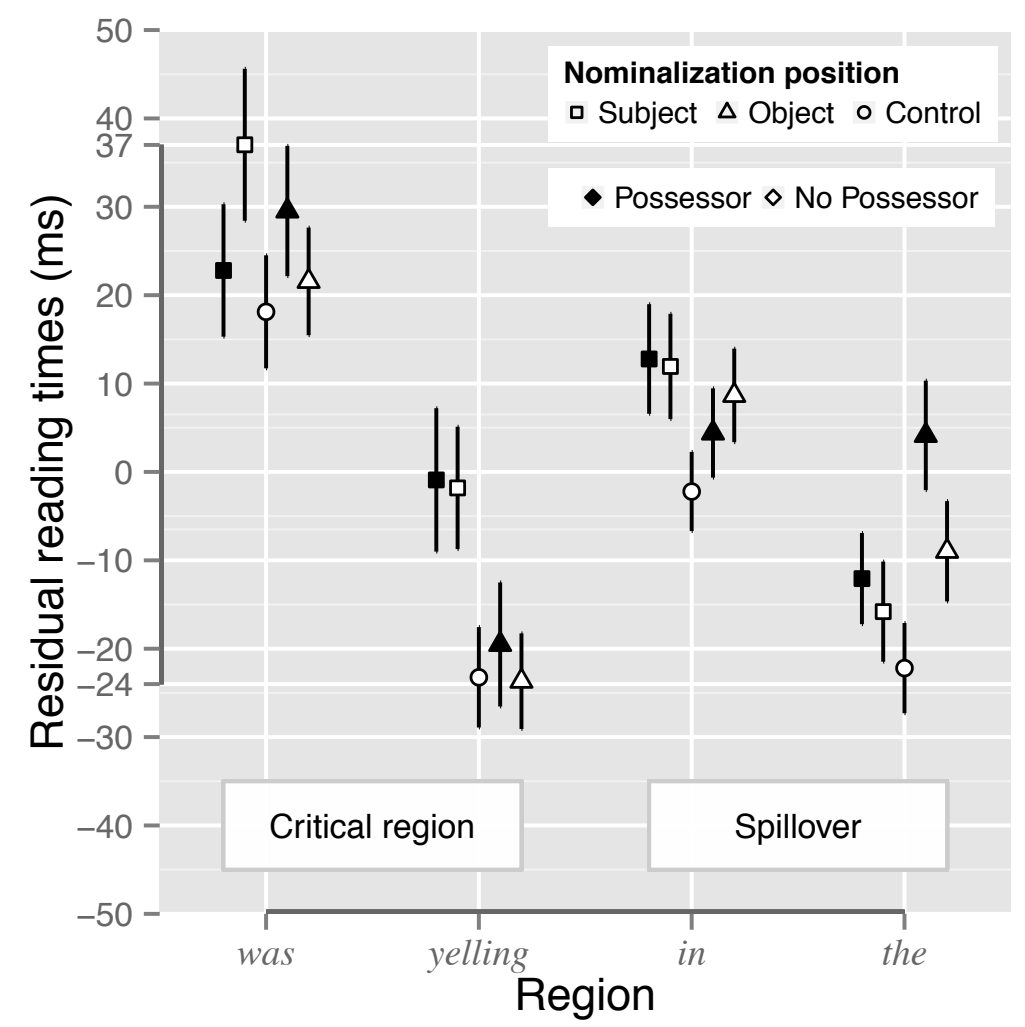

Figure 2: Experiment 1 self-paced residual reading times at critical matrix verb regions and sentence-final PP spillover regions. Error bars show standard error of the mean. The scale of the y-axis shows the range of the minimum and maximum means.

Unless otherwise noted, all reported effects for both RT and accuracy models were significant at $\alpha=.05$ or less.

Results

\section{Self-paced reading times}

The reading times results from Experiment 1 are presented in Figure 2. Overall, we found that increasing the complexity of the intervening subject increased processing difficulty at the matrix verb regions, but no cost for the possessor.

Critical and spillover regions.-There were no significant effects or interactions at the matrix auxiliary, and no significant differences between the interference conditions 
and the control condition. While the auxiliary is the point at which the subject must be retrieved and integrated, by hypothesis, we suggest that the lack of an effect at the aux region is an artifact of the moving-window display. The auxiliary signals a retrieval, but either readers' forward momentum or the predictability of the incoming VP causes readers to advance to the next word before subject retrieval happens or its effects are felt.

Difficulty arose at the matrix main verb. Sentences containing a nominalization in subject, but not object, position led to a slowdown at the matrix verb, a main effect $(\beta=$ $20 \mathrm{~ms}$, S.E. $=8 \mathrm{~ms}$ ). In contrast, there was no significant effect of the possessor, and no interactions. With respect to the control condition, the mean of complex no possessor sentences was significantly different than the control condition $(-2 \mathrm{~ms}$ versus $-23 \mathrm{~ms}$, respectively; $\beta=21 \mathrm{~ms}$, S.E. $=10 \mathrm{~ms}$ ). There were no other significant differences between the interference and control conditions at the main verb.

At the spillover region (e.g., in the kitchen), there were no significant effects at the preposition head within the interference conditions, and no interactions. At the determiner inside the spillover region, sentences where the nominalization occurred in object position without a possessor were significantly slower than the control condition ( $4 \mathrm{~ms}$ versus $22 \mathrm{~ms} ; \beta=26 \mathrm{~ms}$, S.E. $=10 \mathrm{~ms}$ ). However, the maximal converging model contained only random intercepts by participants, and thus assumed no variation among participants for experimental factors. There were no other differences between the interference and control conditions at the spillover regions.

Intervening subject $\mathcal{E}$ embedded VP regions.-There were no significant differences among the interference conditions at the embedded verb of the relative clause (region 13), and the interference conditions were not reliably different from the control condition. At the determiner of the embedded object, all four interference conditions were reliably slower than the control condition. The greatest difference was between sentences with a complex intervener containing a possessor and the control condition $(\beta=68 \mathrm{~ms}$, S.E. $=16 \mathrm{~ms})$. The smallest difference was between complex interveners without a possessor and the control condition $(\beta=35 \mathrm{~ms}$, S.E. $=16 \mathrm{~ms})$. At the head noun of the embedded object, sentences containing a nominalization in the embedded subject position were reliably slower than the control condition (Control mean $=44$ 
ms; Complex+poss: mean $=-18 \mathrm{~ms}, \beta=-63 \mathrm{~ms}$, S.E. $=17 \mathrm{~ms}$; Complex no poss: mean $=-2 \mathrm{~ms}, \beta=-48 \mathrm{~ms}$, S.E. $=18 \mathrm{~ms})$. There were no reliable differences between the control condition and sentences containing a nominalization in object position, and no differences within the interference conditions. Note that the cost for overt embedded subjects shows up one word after the embedded verb, which is similar to the effects in the critical region.

\section{Comprehension question accuracy}

Mean comprehension accuracy for each condition is shown in Table 2. Grand mean accuracy was $75 \%$. Comprehension accuracy for the interference conditions was significantly lower than the control condition (all $p$ 's $<.01$ ). There were no significant differences in accuracy within the interference conditions.

\begin{tabular}{llll}
\hline & \multicolumn{2}{l}{ Nominalization position } & \\
\cline { 2 - 3 } Possessor & Subject & Object & Control \\
\hline No & $72 \%(3 \%)$ & $75 \%(3 \%)$ & $87 \%(3 \%)$ \\
Yes & $72 \%(2 \%)$ & $70 \%(3 \%)$ & \\
\cline { 2 - 4 } & $72 \%(3 \%)$ & $73 \%(3 \%)$ & $87 \%(2 \%)$ \\
\hline
\end{tabular}

Table 2: Experiment 1 comprehension questions, mean accuracy (and standard error) by condition.

\section{Discussion}

The main effect of intervener complexity suggests that a nominalization in subject, but not object, position leads to difficulty when the verb is initially processed. The difficulty at the main verb is consistent with previous findings (Van Dyke \& Lewis, 2003; Van Dyke, 2007), since the verb is the point at which the subject must be retrieved. We also take this to be an interference effect, since it is restricted to configurations where the complex intervener and target subject are both subjects, and thus structurally similar (Van Dyke \& McElree, 2011). Furthermore, comprehension accuracy was reliably lower for experimental conditions - which all included overt subjects - compared to the control condition, which used raising predicates to obviate overt subjects. This is 
consistent with previous findings of interference from embedded, grammatically inappropriate, lexical subjects (Van Dyke \& Lewis, 2003; Van Dyke, 2007). The current experiment extends this effect to sentences that do not vary in their depth of embedding. However, the difficulty at the verb was not due to the presence of a possessor, which had no reliable effects on the processing at the verb or subsequent regions. We take the lack of interference at the critical region for possessors to indicate that subject retrieval targets syntactic properties, and not thematic properties.

Why should complex embedded subjects be more difficult? Assuming the difficulty to arise at retrieval, one potential explanation is that the slowdown for complex interveners is an elaboration effect. Nominalizations are more complex than det+noun nominals in terms of argument structure, the nominalizing morphology, and length. While the materials of Experiment 1 did not make distinct predictions about these possibilities, similar effects of complexity have been observed in the processing of filler-gap and subject-verb dependencies, where increasing the complexity of a to-be-retrieved constituent facilitates the processing at the retrieval site (Hofmeister, 2011). Our results differ in that here complexity led to inhibition, not facilitation. One explanation for these contrasting profiles is that in our materials, and unlike Hofmeister (2011), we manipulated the complexity of an intervening element, not the target constituent ${ }^{2}$. If we assume that increasing the complexity of a constituent increases its accessibility at retrieval, then increasing the complexity of the target will facilitate retrieval, while increasing the complexity of non-target constituents will facilitate misretrieval, and inhibit the retrieval of the target. We return to the issue of complexity in the 'General Discussion' section.

How do these results contribute to our understanding of the retrieval cues? While the lack of possessor interference argues against thematic cues, the slowdown for complex embedded subjects, in conjunction with previous results (Van Dyke \& Lewis,

\footnotetext{
${ }^{2}$ More precisely, since the complexity manipulation varied the structure of a subject-attached modifier clause contained within the target phrase, it manipulated the complexity of both the intervener and the target. However, since the syntactic properties of the target did not vary across conditions, any effect of intervener complexity will still be reflected in the relative differences among complex conditions.
} 
2003; Van Dyke, 2007, a.o.), indicates that the retrieval cues do not uniquely identify one constituent as the subject. A grammatically inappropriate constituent leads to difficulty at the retrieval site, but only when similar to the target. In other words, the retrieval structure at the verb is sufficient to distinguish between the subjects of nominals and the subjects of clauses, but cannot uniquely discriminate between the matrix subject and a structurally similar embedded subject. In Experiment 2, we seek to extend these findings by probing for interference from embedded subjects while varying their syntactic properties.

\section{Experiment 2}

\section{Design $\mathcal{E}$ predictions}

The results of Experiment 1 implicated phrase-structure cues in subject retrieval. We found that increasing the complexity of an intervening nominal only mattered when it was in subject position. In contrast, we found no comparable difficulty for the presence of a possessor subject inside the nominalization, despite its being thematically similar to the target matrix subject. These patterns suggest that the retrieval cues available at a verb characterize subjects in terms of phrase-structure, and not their thematic properties. In English, possessors can be differentiated from subjects of verbs by two possible cues: either case, i.e. [GENITIVE] versus [NOMINATIVE], or specific structural position, i.e. [SPEC-D] versus [SPEC-T], respectively.

In Experiment 2, we extend the investigation of subject interference to a different aspect of similarity, namely the abstract case features of subjects. Abstract case, or "Case", is distinct from overt morphological case, and refers to the morphosyntactic head-dependent relation by which a predicate licenses the presence of a nominal argument in the clause. The current experiment manipulated Case similarity between a matrix and embedded subject by varying the syntactic properties of the verb which embedded the clause containing the intervening subject. Using structures such as those shown in (20), we compared the nominative subject of a finite clause ('S-complement' sentences; 20a) to the accusative subject of a non-finite clause (20b) using so-called 'exceptional case-marking' (ECM) verbs like believe. 
(20) a. The explorer who believed that [TP the monster was prowling the ruins] was insane...

b. The explorer who believed [тР the monster to be prowling the ruins] was insane...

Crucially, while the subject of an ECM complement, like the monster in (20b), differs from the nominative embedded subject of (20a) in its Case feature, both elements occupy the highest structural subject position of the embedded clause. Thus, the embedded subjects of both structures in (20) are similar in terms of their syntactic position, but the embedded subject of the ECM structure is dissimilar to the matrix subject in its Case feature.

To further disassociate Case and position, we also compared the subject interveners of S-complement and ECM structures (20) to object control structures, such as that shown below in (21). As in the ECM sentences, the potentially interfering element bears accusative Case, but occupies the matrix object position, which is linked to the embedded subject position (PRO) via the Control dependency. The intervening element in the object control structures is thus maximally dissimilar to the target matrix subject: they mismatch in both Case and position.

(21) The explorer who persuaded the monster [тр to prowl the ruins ] was insane...

Experiment 2 was also designed to extend the complexity effect of Experiment 1 to noun-noun compounds like the ancient alien monster, reasoning that the initial noun will be erroneously parsed as the head of the embedded subject, and reanalyzed as a modifier element when the second member of the compound is encountered. Reanalysis should thus require elaboration of the intervener, resulting in a stronger encoding and potentially increasing the probability of its (mis)retrieval. The complexity manipulation of Experiment 2 is similar to that of Hofmeister (2011), who found that processing at the verb was easier when its subject was a modified-NP like an alleged Venezuelan communist compared to a simpler nominal like a communist. As in Experiment 1, if complex constituents are easier to retrieve, then we expect complex interveners to increase difficulty at the matrix verb by inhibiting retrieval of the target. Furthermore, 
noun-noun compounds do not contain the thematic structure of the nominalizations used in Experiment 1, so that replicating the complexity effect in Experiment 2 would show that the effect was not due to resolving additional thematic links.

The resulting experimental design was $3 \times 2$, with factors for embedded structure (S-complement, ECM, Object Control) and intervener complexity (noun-noun compound, det+noun). The potential dimensions of similarity are schematized below:

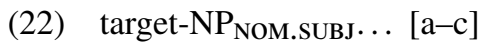
$\ldots$ Aux $_{\text {NOM?subJ? }}+$ MainV

a. S-comp:

believes [cP (that) [тP $\mathrm{NP}_{\text {NOM.subu was } \mathrm{V} \ldots]]}$

b. ECM:

believes [Tт $\mathrm{NP}_{\mathrm{ACC} . \text { SUBJ }}$ to $\mathrm{V} \ldots$...]

c. Object Control:

persuaded $\mathrm{NP}_{\text {ACC. OBJ }}[\mathrm{CP}[\mathrm{TP} P R O$ to $\mathrm{V} . .]$.

The critical region is the matrix auxiliary verb, where the subject is retrieved. If the target of the verb's retrieval identified by structural position, then the intervening element of both S-comp and ECM conditions will be similar to the target matrix subject. We thus expect that both of the subject intervener conditions will engender more interference than the Object Control sentences. In contrast, if the verb's cues target Case properties, i.e. Nominative elements, then only S-complement interveners will match the case retrieval cue-both ECM and Object Control conditions contained ACcusativE interveners. If the verb uses retrieval cues for both case and structural position, then S-comp interveners will match both cues, ECM sentences will match only the position cue, and Object Control will match neither cue. We thus expect a cline of difficulty, with the greatest interference in S-comp conditions (full match), followed by ECM conditions (partial match), and Object Control conditions the easiest (mismatch).

For the complexity manipulation, the predictions are twofold. If the subject-complexity effect of Experiment 1 was due to the additional thematic links of the event nominalization, then we expect this effect to be absent in Experiment 2, since the compounds lack such propositional structure. Furthermore, if the effect of complexity is modulated 
by the degree of similarity to the target of retrieval, then we expect greater difficulty for complex interveners, but this difficulty should be greatest in the S-complement sentences due to greater similarity with the target matrix subject.

\section{Method}

Participants. - A Sample set of materials for Experiment 2 is shown in Table 3. Experimental materials consisted of 36 item sets arranged in a $2 \times 3$ factorial design, manipulating intervener complexity (complex/simple) and the properties of the verb that embedded the clause containing the intervener (ECM, S-complement, Object Control). The complexity manipulation compared simple det+noun subjects, e.g. the monster, to noun-noun compounds with an adjective modifier, e.g. the ancient alien monster. The critical region was the matrix auxiliary+verb sequence, e.g. was yelling.

As in Experiment 1, we used sentence-initial adverbial phrases and sentence-final prepositional phrases. The first three word regions, including the target matrix subject, were the same for all conditions, e.g. the explorer who. The fourth region was the verb embedding the intervener, e.g. believe for ECM/S-comp and persuade for object control structures. Region 5 was the complementizer that, and so only occurred in S-complement conditions. Regions 6-9 comprised the intervener. In simple intervener conditions, this was a singular and definite the+noun sequence, while in complex intervener conditions this was an adjective-modified singular and definite

Table 3: Sample set of materials for Experiment 2. Intervener constituents are underlined. Not shown: Initial adverbial phrase and sentence-final prepositional phrase. 
noun-noun compound, i.e. the+adj+noun-noun. The regions following the intervener comprised the embedded VP region, containing the embedded verb along with necessary tense/auxiliaries, e.g. was/to (be)+prowl, as well as the embedded object, e.g. the ruins. The embedded region always ended with a prepositional phrase, e.g. for the expedition, designed to favor VP-level attachment and provide a buffer between the embedded object and critical regions. The critical region was always of the form aux+intransitive predicate, and followed by a prepositional phrase that served as the spillover region.

The 36 experimental item sets were combined with 72 filler sentences. Filler sentences were designed to be multi-clausal structures of a similar length to the experimental items. In order to guard against participants using the syntactic properties to identify experimental items, the filler sentences contained a mixture of finite and nonfinite complement clauses, relative clause-modified arguments, noun-noun compounds, and gerunds with a controlled PRO subject.

Participants. - Forty-two participants from the University of California, Santa Cruz community received $\$ 15$ for participation in the experiment. All participants gave informed consent.

Procedure.- Reading Time data was collected using the Linger software, using a procedure identical to that described above for Experiment 1.

Analysis. - The analysis of Experiment 2 was almost identical to that described for Experiment 1, but differed in the coding scheme for experimental factors. Extreme observations less than $50 \mathrm{~ms}$ and greater than $3000 \mathrm{~ms}$ were removed (.002\%). Five participants were removed for extremely low comprehension accuracy $(<65 \%)$. Reading times were analyzed in regions consisting of a single word, as shown below. We report only residual reading times, computed using a procedure identical to that described in Experiment 1. Outliers were removed by computing z-scores for residual RTs, by region and condition, then removing those observations whose z-score exceeded $|3|$ $(2 \%)$.

(23) Experiment 2 analysis regions:

Target The $_{1}$ explorer $_{2}$ 


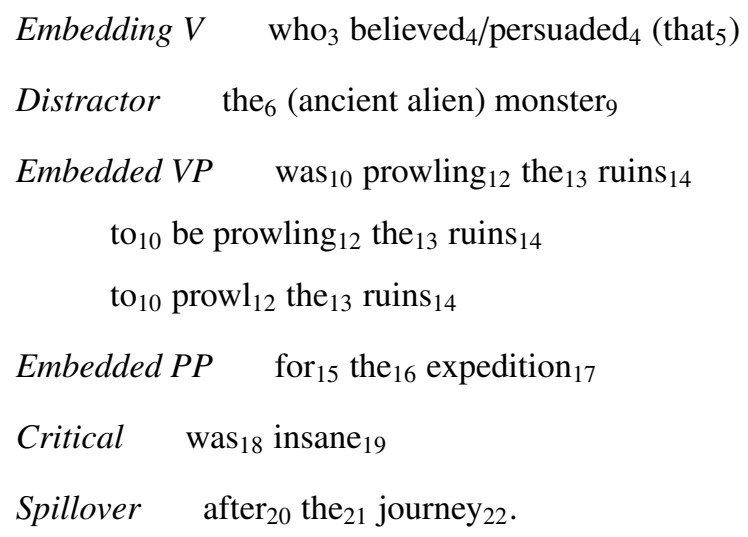

The residual RTs at each region were analyzed in a series of linear mixed-effects models. Each model used the maximal random effects structure in the sense of Barr et al. (2013, see Experiment 1). Coefficient contrasts for the similarity manipulations used a Helmert coding scheme, which compared (i) S-complement to ECM sentences (the 'subject intervener' conditions), and (ii) object control sentences to the mean of subject intervener conditions. In other words, the Helmert contrasts compared the effect of case within sentences with an intervening subject, and the effect of object interveners to subject interveners.

Contrasts for intervener complexity used deviation coding $(.5,-.5)$, with noun-noun compounds as the positive coefficient. Pairwise comparisons were evaluated using linear mixed-effects models fit to data for the two conditions of interest only, using treatment coding so that coefficient estimates reflect differences in the condition means. To avoid confusion with the experimental models, we report the $95 \%$ c.i. of the pairwise coefficient, determined by a Wald test. As in Experiment 1, we interpret significant coefficients as those whose $t / z$ exceeded $|2|$.

Comprehension question accuracy was analyzed using logistic regression models, using the same coding scheme described above for the residual RTs. Since comprehension questions were the same for each item set, and so between items, comprehension models included only random intercepts for items. Unless otherwise noted, all reported coefficients for both RT and comprehension models were significant at $\alpha=.05$ or less. 


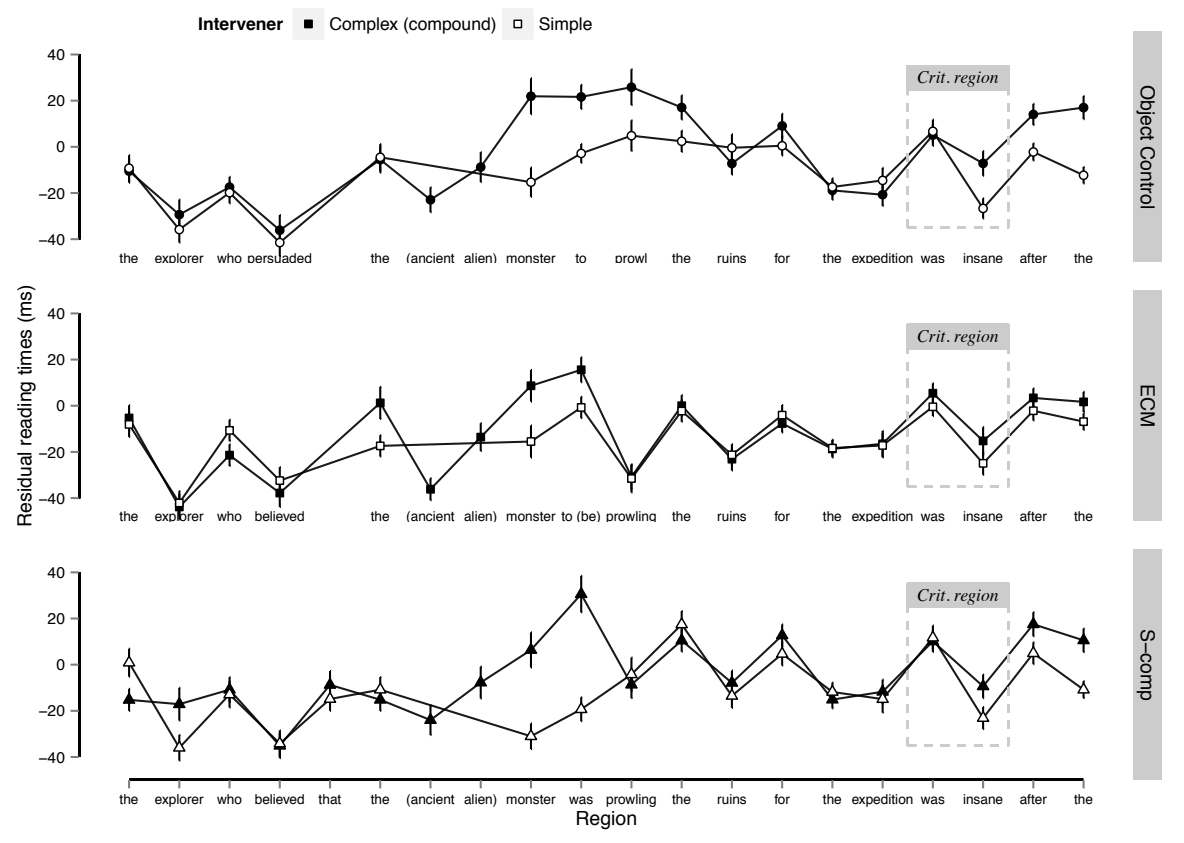

Figure 3: Experiment 2 residual reading times, for all conditions, summarizing mean residual reading Times (y-axis) for each experimental region (x-axis). Error bars show one standard error of the mean.

Results

Self-paced reading times

Reading times for all conditions are summarized in Figure 3. As in Experiment 1 , we found an immediate slowdown at the verb for sentences containing complex interveners. This was followed by a delayed interaction of complexity and structural similarity (e.g. believe versus persuade), such that the difficulty for complex interveners was attenuated in the ECM conditions.

Critical $\mathcal{E}$ Spillover regions._-At the critical auxiliary, there were no significant effects for experimental factors or their interactions. As in Experiment 1, we suggest that the auxiliary initiates subject retrieval, but the effects show up one word downstream as an artifact of the self-paced reading procedure.

At the matrix main verb, sentences with an intervening noun-noun compound were read reliably slower than sentences with a simple DP intervener $(\beta=12 \mathrm{~ms}$, S.E. $=$ $4 \mathrm{~ms}$ ). The effect of structure, however, was not significant: S-comp sentences were 
not reliably different from ECM sentences ( $\beta=3 \mathrm{~ms}$, S.E. $=2 \mathrm{~ms}$ ), and object control sentences were not reliably different from the pooled subject intervener conditions $(\beta=$ $1 \mathrm{~ms}$, S.E. $=1 \mathrm{~ms})$. There were no interactions. Pairwise comparisons at the matrix main verb revealed that the effect of complexity was significant only for Object Control structures $(95 \%$ c.i. [5 ms, $36 \mathrm{~ms}])$ and trending significant for S-comp structures (95\% c.i. [0 ms, $27 \mathrm{~ms}], \mathrm{t} / \mathrm{z}=1.97)$.

The slowdown for complex interveners persisted to the spillover region, but differences emerged between structures. The effect of complexity was significant throughout the spillover region, with a slowdown for complex interveners at the preposition $(\beta=8$ $\mathrm{ms}$, S.E. $=4 \mathrm{~ms})$, the determiner $(\beta=21 \mathrm{~ms}$, S.E. $=5 \mathrm{~ms})$, and the head noun $(\beta=23$ ms, S.E. $=9 \mathrm{~ms}$ ). The effect of structure was also significant, such that S-complement structures were read significantly more slowly than ECM structures at the preposition $(\beta=5 \mathrm{~ms}$, S.E. $=2 \mathrm{~ms})$ and the head noun $(\beta=10 \mathrm{~ms}$, S.E. $=5 \mathrm{~ms})$, but there were no significant differences between the Object Control structures and subject intervener conditions at any region. The interaction of complexity and structure was trending significant at the head noun, suggesting that the cost for complex interveners was more acute in Object Control conditions than subject intervener conditions $(\beta=10 \mathrm{~ms}$, S.E. $=5 \mathrm{~ms} ; \mathrm{t}=1.916$ ). However, the maximal model at the spillover noun did not contain random slopes for the interaction terms, either by-participant or by-item, and thus pooled the error across conditions. Pairwise comparisons revealed that the effect of complexity was not reliable for ECM structures at any spillover region. Complex interveners led to a slowdown for Object Control sentences at the preposition (95\% c.i. [ $1 \mathrm{~ms}, 32 \mathrm{~ms}]$ ), determiner (95\% c.i. [ $9 \mathrm{~ms}, 48 \mathrm{~ms}]$ ), and head noun ( $95 \%$ c.i. [4 ms, $82 \mathrm{~ms}])$. The slowdown for complex intervener was also significant in S-complement structures, but only at the determiner (95\% c.i. [7 ms, $35 \mathrm{~ms}]$ ). Pairwise comparisons also revealed that the effect of structure at the preposition was driven by differences within the complex intervener conditions, such that complex S-complement sentences were reliably slower than complex ECM sentences (95\% c.i. [1 ms, $28 \mathrm{~ms}]$ ), but there were no reliable differences within simple intervener conditions.

Relative pronoun $\mathcal{E}$ intervener regions.- There were no significant effects or interactions in models fit to the relative pronoun region. Visual inspection suggested 
that there were significant differences among structures, which was confirmed in pairwise comparisons. However, there were no lexical differences between conditions at this point, and the moving-window display precluded any preview effects, so we take these differences to be spurious. Models fit to the embedding verb region, i.e. believe for S-comp/ECM and persuade for Object Control conditions, also did not show any significant effects for experimental factors or their interactions.

At the intervener phrase, i.e. the (ancient alien) monster, there were no significant effects or interactions at the initial determiner. There were significant effects of both complexity and structure at the head noun (monster). Complex conditions were read significantly more slowly than simple conditions $(\beta=32 \mathrm{~ms}$, S.E. $=7 \mathrm{~ms})$. There was also a significant effect of structure, reflecting a slowdown for Object Control sentences relative to the subject intervener conditions $(\beta=5 \mathrm{~ms}, \mathrm{~S} . \mathrm{E} .=2 \mathrm{~ms})$. There were no significant interactions, though note that the maximal converging model did not contain random slopes for the interaction term, either by-item or by-participant. Pairwise comparisons revealed that the main effect of complexity was driven by a slowdown for complex interveners at the intervener head noun in S-comp conditions (95\% c.i. [13 ms, $62 \mathrm{~ms}])$ and Object Control conditions (95\% c.i. [17 ms, $60 \mathrm{~ms}])$. The effect of complexity was not significant in the ECM conditions.

Embedded VP regions $\mathcal{E}$ pre-critical regions.- Reading times at the embedded verb phrase showed effects of structure, but no effect of intervener complexity. At the embedded verb, S-comp conditions were read more slowly than ECM conditions $(\beta=$ $12 \mathrm{~ms}$, S.E. $=3 \mathrm{~ms}$ ), and Object Control conditions were read more slowly than subject intervener conditions $(\beta=11 \mathrm{~ms}$, S.E. $=2 \mathrm{~ms})$. There was no effect of intervener complexity, and no interactions. The maximal model did not contain random slopes for the interaction terms, either by-participant or by-item. In pairwise comparisons, the effect of intervener complexity was significant only for Object Control sentences $(95 \%$ c.i. [1 ms, $40 \mathrm{~ms}])$. Pairwise comparisons also revealed significant differences for all structures. Within complex intervener conditions, Object Control sentences were reliably slower than either S-comp sentences (95\% c.i. [15 ms, $54 \mathrm{~ms}$ ]) or ECM sentences (95\% c.i. [32 ms, $79 \mathrm{~ms}$ ), while S-comp sentences were reliably slower than ECM sentences ( $95 \%$ c.i. [3 ms, $42 \mathrm{~ms}$ ]). Within simple intervener conditions, S-comp sen- 
tences were reliably slower than ECM sentences ( $95 \%$ c.i. $[7 \mathrm{~ms}, 48 \mathrm{~ms}]$ ). Simple Object Control sentences were also significantly slower than simple ECM sentences (95\% C.I. [21 ms, $53 \mathrm{~ms}$ ]), but there was no difference between simple S-comp and Object Control sentences.

There were significant effects of structure at the embedded object regions, such that S-comp conditions were read more slowly than ECM conditions at both the determiner $(\beta=9 \mathrm{~ms}$, S.E. $=2 \mathrm{~ms})$ and head noun $(\beta=5 \mathrm{~ms}$, S.E. $=3 \mathrm{~ms})$ of the embedded object. There were no other significant effects, but the interaction of complexity and structure was trending significant at the determiner, suggesting that the effect of complexity was more acute in Object Control conditions compared to subject intervener conditions $(\beta=5 \mathrm{~ms}, \mathrm{~S} . \mathrm{E} .=3 \mathrm{~ms} ; \mathrm{t}=1.927)$. The maximal model at both the determiner and head noun did not contain random by-item slopes for the interaction terms, while the maximal model at the head noun did not contain by-participant random slopes for the complexity factor. Pairwise comparisons revealed a slowdown for complex interveners at the determiner, but only for Object Control structures (95\% c.i. [1 ms, 29 $\mathrm{ms}]$ ). Within complex intervener conditions, S-comp sentences were reliably slower than ECM sentences at the embedded object noun (95\% c.i. [1 ms, $30 \mathrm{~ms}])$, where Object Control sentences were also reliably slower than ECM sentences (95\% c.i. [1 ms, $32 \mathrm{~ms}]$ ). The slowdown for complex Object Control sentences to complex ECM sentences was trending significant at the determiner $(95 \%$ c.i. $[0 \mathrm{~ms}, 33 \mathrm{~ms}], t / z=$ 1.97). Simple S-comp sentences were reliably slower than simple ECM sentences at the determiner (95\% c.i. [4 ms, $34 \mathrm{~ms}$ ]), while a slowdown for simple Object Control sentences relative to simple ECM sentences was significant at the embedded object head noun ( $95 \%$ c.i. [2 ms, $39 \mathrm{~ms}])$.

The pre-critical regions at the end of the embedded clause, e.g. for the expedition, showed fleeting effects of structure, presumably due to spillover from the embedded VP regions. At the preposition head, S-comp conditions were read more slowly than ECM conditions $(\beta=7 \mathrm{~ms}$, S.E. $=2 \mathrm{~ms})$. This model did not contain by-participant random slopes for the interaction terms. Pairwise comparisons revealed that the effect of structure at the pre-critical preposition was driven by differences among the complex intervener conditions, where both Object Control and S-comp sentences reliably slower 
than ECM sentences (Object Control 95\% c.i. [0 ms, 35 ms]; S-comp 95\% c.i. [8 $\mathrm{ms}, 33 \mathrm{~ms}])$. There were no significant effects of complexity or interactions at the pre-critical preposition, and no significant effects whatsoever at either the pre-critical determiner or noun.

\section{Comprehension question accuracy}

Mean accuracy scores on comprehension questions are shown in Table 4. Overall, we found significant effects of structure, but no reliable effect of intervener complexity.

\begin{tabular}{llll}
\hline & \multicolumn{3}{c}{ Structure } \\
\cline { 2 - 4 } Intervener & S-comp & ECM & Object Control \\
\hline Simple & $80 \%(2 \%)$ & $79 \%(2 \%)$ & $73 \%(2 \%)$ \\
Complex & $77 \%(2 \%)$ & $79 \%(2 \%)$ & $72 \%(2 \%)$ \\
\cline { 2 - 4 } & $79 \%(2 \%)$ & $79 \%(2 \%)$ & $73 \%(2 \%)$ \\
\hline
\end{tabular}

Table 4: Experiment 2 comprehension accuracy, condition means (and standard errors).

Grand mean accuracy on comprehension questions was 77\%. Overall, Object Control conditions were significantly less accurate than subject intervener conditions (Scomp, ECM; $\beta=-.13 \mathrm{~ms}$, S.E. $=.03 \mathrm{~ms}$ ). There were no effects for intervener complexity or interactions of complexity and structure. Within complex intervener conditions, object control sentences were significantly less accurate than subject intervener sentences $(\beta=-.12 \mathrm{~ms}$, S.E. $=.05 \mathrm{~ms})$. In pairwise comparisons, complex Object Control sentences were reliably less accurate than complex ECM sentences $(\beta=-.43 \mathrm{~ms}$, S.E. $=$ $.17 \mathrm{~ms}$ ), but the difference between complex Object Control and complex S-comp was only trending significant $(\beta=-.28 \mathrm{~ms}$, S.E. $=.16 \mathrm{~ms}, \mathrm{p}=.09)$. Within simple intervener conditions, Object Control sentences less accurate than sentences with a subject intervener $(\beta=-.14 \mathrm{~ms}$, S.E. $=.05 \mathrm{~ms})$. In pairwise comparisons, complex Object Control were reliably less accurate than both complex S-comp sentences $(\beta=-.45 \mathrm{~ms}$, S.E. $=.17 \mathrm{~ms})$ and complex ECM sentences $(\beta=-.39 \mathrm{~ms}$, S.E. $=.17 \mathrm{~ms})$. 


\section{Discussion}

The results of Experiment 2 suggest that increasing the complexity of a subject leads to difficulty at a subsequent VP. When a noun-noun compound intervened between a verb and its target subject, the reading times at the matrix main verb were significantly longer than when the intervener was a simple Det+Noun constituent. Furthermore, while this difficulty arose at the matrix main verb, there was no effect of complexity at the pre-critical regions, indicating that the difficulty arose at the retrieval site, the verb. However, the complexity effect was attenuated in ECM structures, with no reliable differences between complex and simple ECM sentences at the intervening head noun, the critical main verb, or the spillover region. Thus, we found that complex interveners lead to difficulty in the retrieval required at a verb, but the strength of this difficulty is modulated by the syntactic properties of the intervener.

In contrast to the immediate effect of intervener complexity, we also observed effects of structure at the post-verbal regions of both the embedded and matrix clause. Within the subject intervener conditions, S-complement sentences were consistently more difficult than ECM conditions. We also found that Object Control sentences were reliably more difficult than subject intervener conditions, reflected in longer reading times and lower comprehension accuracy. Consider first the differences among the subject intervener conditions. Whereas the complexity effect for S-complement structures - the same structures used in Experiment 1-persisted to the spillover region, there was no corresponding slowdown for ECM structures. Thus, the retrieval cues provided by the verb are able to distinguish between the embedded subjects of S-complement and ECM structures.

While both S-complement and ECM interveners are structural subjects, they are distinguished by their case properties: NOMINATIVE for S-complement, and Accusative for ECM. Alternatively or additionally, they differ in the syntactic properties of their dominating clause. S-complement verbs embed a finite (tensed) clause, while ECM verbs embed a non-finite (untensed) clause. The target subject was always a nominative subject of a finite clause. Thus, in terms of the retrieval cues, differences within the subject intervener conditions indicate that the embedded subjects of S-comp, but not 
ECM, structures match the subject cues provided by the verb. The relevant cues, then, would target the nominative subject of a finite clause.

This conclusion is at odds with the patterns observed for the Object Control conditions, though the results are somewhat harder to interpret. We found that Object Control sentences were consistently more difficult than ECM sentences, with a cost for complex interveners and a slowdown at the matrix spillover region, but the difference between S-complement and Object Control structures was not reliable at the matrix VP. Retrieval cues for a nominative subject constituent should reduce interference in the Object Control sentences, where the intervener is an accusative object. The only point at which Object Control sentences were reliably more difficult than S-complement sentences was at the embedded verb, immediately after the embedded subject gap, potentially implicating a cost for resolving the identity of PRO. If the slowdown for Object Control structures at the spillover region reflects interference, then something about these structures is 'subject-like'. The accusative object is a poor candidate, since it is maximally dissimilar from the target nominative subject. One explanation is that the observed difficulty in Object Control sentences reflects interference from the embedded PRO subject. While PRO has traditionally been analyzed as either case-less (Bouchard, 1984) or bearing a special null case (Chomsky \& Lasnik, 1993), more recently Landau (2006) has proposed that PRO bears standard nominal case. Under this analysis, the implicit subject of the Object Control sentences would bear nominative case, just like S-complement interveners, and engender interference when the target of retrieval is a nominative subject. Thus, there is some supporting evidence from syntactic theory that the PRO subject of an Object Control sentence is sufficiently subject-like to engender interference, at least at a sufficiently abstract level of syntactic representation.

As in Experiment 1, complex interveners led to difficulty at the matrix verb regions. The results of Experiment 2 extend the effect of complexity to noun-noun compounds (see Hofmeister, 2011, for a similar manipulation) We return to these issues in the general discussion, but note that the noun-noun compounds used in Experiment 2 lack the internal argument structure of the event nominalizations used in the previous experiment. Thus, the results of Experiment 2 extend the complexity effect to include noun-noun compounds, suggesting that the whatever is more difficult about complex 
constituents, the effect is not due to the need to establish additional thematic bindings.

A potential worry in these results is the presence of a local ambiguity in the ECM conditions. Until the disambiguating embedded verb, ECM structures are consistent with continuations where the intervener is parsed as either a matrix object or embedded subject-i.e. an 'NP/S' ambiguity (Sturt, Pickering \& Crocker, 1999). If the intervener is initially parsed as the matrix object, then this lingering misanalysis might give rise to the observed attenuation of the subject-complexity effect by increasing structural dissimilarity - the intervener would no longer be a structural subject. Experiment 3 was designed to address the role of ambiguity, while using eye-tracking to further probe the timecourse of intervener complexity and structural similarity.

\section{Experiment 3}

The reading times of Experiment 2 showed a main effect of intervener complexity at the main verb, and a delayed effect of structural similarity. These contrasting effects potentially implicate a distinct timecourse of processing at the verb. For instance, it may be that retrieval starts with a general cue, like [NP], giving rise to the complexity effect, and then narrows down using additional cues that give rise to later effects of structural similarity.

To better understand the timecourse of processing at the verb, Experiment 3 was designed to replicate the effects of Experiment 2, while using an eye-tracking methodology. If the distinct profiles of intervener complexity and structural similarity are the result of early versus late processing, then we this may be reflected in the corresponding reading time measures, discussed below.

Additionally, a key finding of Experiment 2 was an interaction of intervener complexity and structural similarity in the spillover region, with a slowdown for complex interveners in S-complement - but not ECM - structures. One interpretation of this is that the interference caused by an ECM intervener is mitigated by structural dissimilarity. However, it may be that an early effect of similarity in the ECM conditions was masked by persistent effects of ambiguity. To better understand the role of ambiguity in the ECM sentences, the materials of Experiment 3 also included ambiguous versions 
of the S-complement structures, constructed by removing the complementizer that.

\section{Method}

\section{Participants}

Forty participants from the University of California, Santa Cruz community participated in the experiment. All participants gave informed consent, and received course credit or $\$ 10$ for participating.

\section{Procedure}

Eye movements were recorded using an Eyelink 1000 (SR Research Ltd., Ottawa, Canada), which recorded the position of the eye twice every millisecond with a spatial resolution of 0.01 degrees. A chin rest was used to minimize head movement. Calibration was performed at the beginning of the experiment, and throughout when necessary, using a 9-point grid.

Each trial began with a gaze trigger. Upon detection of a stable fixation on this trigger, the full sentence was presented. Participants indicated completion of the trial by pressing a button on a gamepad, after which a comprehension question was presented in its entirety. Answers to the comprehension questions (yes/no) were entered by pressing the appropriate button on the gamepad.

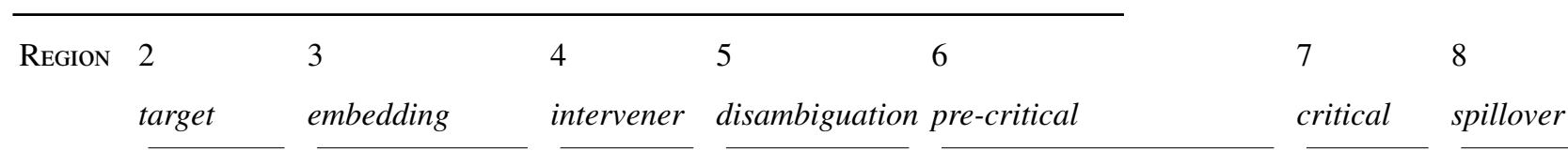

s-comp the explorer who believed that the monster was prowling the ruins for the expedition was insane after the - АMв. the explorer who believed the monster was prowling the ruins for the expedition was insane after the ECM the explorer who believed the monster to be prowling the ruins for the expedition was insane after the OBJ CTRL the explorer who persuaded the monster to prowl the ruins for the expedition was insane after the XCOMPLEXITY the ancient alien-monster Table 5: Sample materials for Experiment 3, with regions of interest for eye tracking measures. 


\section{Materials}

A sample set of materials and regions of analysis are provided in Table 5. The materials of Experiment 3 are largely identical to those of Experiment 2, with one exception. Since the ECM conditions were ambiguous up to the embedded verb, an additional condition created ambiguous S-complement versions by dropping the complementizer that. The resulting experimental design was $2 \times 4$, manipulating complexity (simple/complex) and embedded clause type (S-comp-ambiguous, S-comp+ambiguous, ECM, and Object Control). Experimental materials consisted of 40 item sets distributed across 8 lists in a Latin Square design, and combined with 80 filler sentences of similar length. All sentences were grammatical.

Analysis

Artifact rejection was performed using the University of Massachusetts Eye Tracking Lab Eye Doctor software. Trials containing blinks or evidence of tracking loss at the critical region were removed. Within trials, blinks were removed, while fixations drastically off the line of text were treated as blinks and removed. An automatic process combined fixations less than $80 \mathrm{~ms}$ that occurred within 1 character of a sequentially adjacent fixation, while other fixations less than $80 \mathrm{~ms}$ and greater than $1000 \mathrm{~ms}$ were removed (Staub, 2011; Kwon \& Sturt, 2014).

Regions of interest are annotated in the sample materials shown in Table 5. At the critical region, the auxiliary verb was pooled with the main verb due to high skipping rates. Dependent measures were computed by an automated process, then imported to $\mathrm{R}$ for statistical analysis.

In what follows, we report the results in terms of four dependent measures. In interpreting these measures, we follow previous work on interference using eye-tracking (e.g. Logačev \& Vasishth, 2012). First pass times are the sum of all fixations in a region before exiting to either the left or the right - an estimate of early processing stages, including difficulty in integrating the text during reading (Inhoff, 1984). Gopast times are all fixations in a region before exiting to the right, and thus include time spent regressing to previous regions. We take go-past times to reflect difficulty in integrating a word with the preceding context (Clifton, Staub \& Rayner, 2007), and note 
that previous studies of subject interference have observed interference in go-past times (Van Dyke, 2007; Van Dyke \& McElree, 2011) Total times are the sum of all fixations in a region, including regressions and re-reading. Finally, first-pass regressions out are the observed proportions of regressions (backwards saccades) out of a given region, immediately following a first-pass fixation on that region. Regressions from subsequent fixations are not included. We take go-past times to reflect processing difficulty at the given region, and in particular difficulty in re-analysis (Frazier \& Rayner, 1982; Meseguer, Carreiras \& Clifton, 2002).

Dependent measures at each region were modeled with a series of linear mixedeffects models, using the lme4 package in R (Bates et al., 2013; R Core Team, 2013). Outliers were removed by computing $z$-scores by region and condition, excluding those observations greater than $|3|$ standard deviations. As in Experiment 2, experimental factors were coded using Helmert contrasts, comparing: (i) ambiguous S-complement conditions to ECM conditions (the 'ambiguous conditions'); (ii) the pooled RTs from the ambiguous conditions to the unambiguous S-complement sentence (the 'SPEC-T conditions'), and (iii) the pooled SPEC-T conditions to control verb conditions. Contrasts for intervener complexity used deviation coding $(.5,-.5)$, with complex interveners as the positive coefficient. Significant effects were determined as those coefficient estimates with a $t / z$-score greater than 2 (Gelman \& Hill, 2007). Unless otherwise noted, all reported coefficients were significant at $\alpha=.05$.

Results

Comprehension accuracy results are shown in Table 6. Grand mean accuracy on comprehension questions was $78 \%$, with condition means ranging from $76 \%$ for complex intervener S-complement conditions to $80 \%$ for simple intervener S-complement conditions. Complex interveners led to significantly lower accuracy in S-complement sentences $(\beta=-.59 \mathrm{~ms}$, S.E. $=.27 \mathrm{~ms})$. Otherwise, there were no other effects for experimental factors, and no interactions.

A summary of Experiment 3 reading time data for all measures is shown in Table 7. Reading times for Experiment 3 showed clear evidence of ambiguity in early measures across the embedded region, while later measures showed an interaction between 
intervener complexity and structural similarity.

\section{R7-8: Critical region and spillover}

Results at the critical region for all measures are summarized in Table 4. At the matrix auxiliary and main verb region, there was a significant interaction of intervener complexity and structure in go-past times, with complex interveners leading to significantly slower go-past times in the finite S-complement compared to ECM conditions $(\beta=62 \mathrm{~ms}$, S.E. $=23 \mathrm{~ms})$. There were no differences within the S-complement conditions. The pattern was more robust in the proportion of regressions out, with finite S-complements showing an overall greater proportion of regressions out than ECM conditions $(\beta=.22$, S.E. $=.11 ; \mathrm{z}=1.97)$. The interaction effect was also present in regressions out, such that complex interveners led to significantly more regressions in the S-complement conditions compared to the ECM condition $(\beta=.71$, S.E. $=.22)$. Scomplement conditions also showed reliably slower total times overall than the ECM condition $(\beta=58 \mathrm{~ms}$, S.E. $=17 \mathrm{~ms})$. There were no significant effects in first-pass times for experimental factors, and no significant effects in any measure at the spillover region.

\section{R3: Embedding verb $\mathcal{E}$ relative pronoun region}

The addition of the disambiguating complementizer that led to significant differences in structure at all measures except regressions out. Unambiguous S-complement conditions were slower than ambiguous S-complements in first-pass times $(\beta=86 \mathrm{~ms}$,

\begin{tabular}{rlll}
\hline & Simple & Complex & (all) \\
\hline Scomp & $80 \%(3 \%)$ & $76 \%(3 \%)$ & $78 \%(3 \%)$ \\
Ambig & $78 \%(3 \%)$ & $78 \%(3 \%)$ & $78 \%(3 \%)$ \\
ECM & $78 \%(3 \%)$ & $78 \%(3 \%)$ & $78 \%(3 \%)$ \\
Obj. Control & $76 \%(3 \%)$ & $77 \%(3 \%)$ & $76 \%(3 \%)$ \\
$($ all) & $78 \%(3 \%)$ & $77 \%(3 \%)$ & $78 \%(3 \%)$ \\
\hline
\end{tabular}

Table 6: Experiment 3 comprehension accuracy means (and standard errors) by condition. 


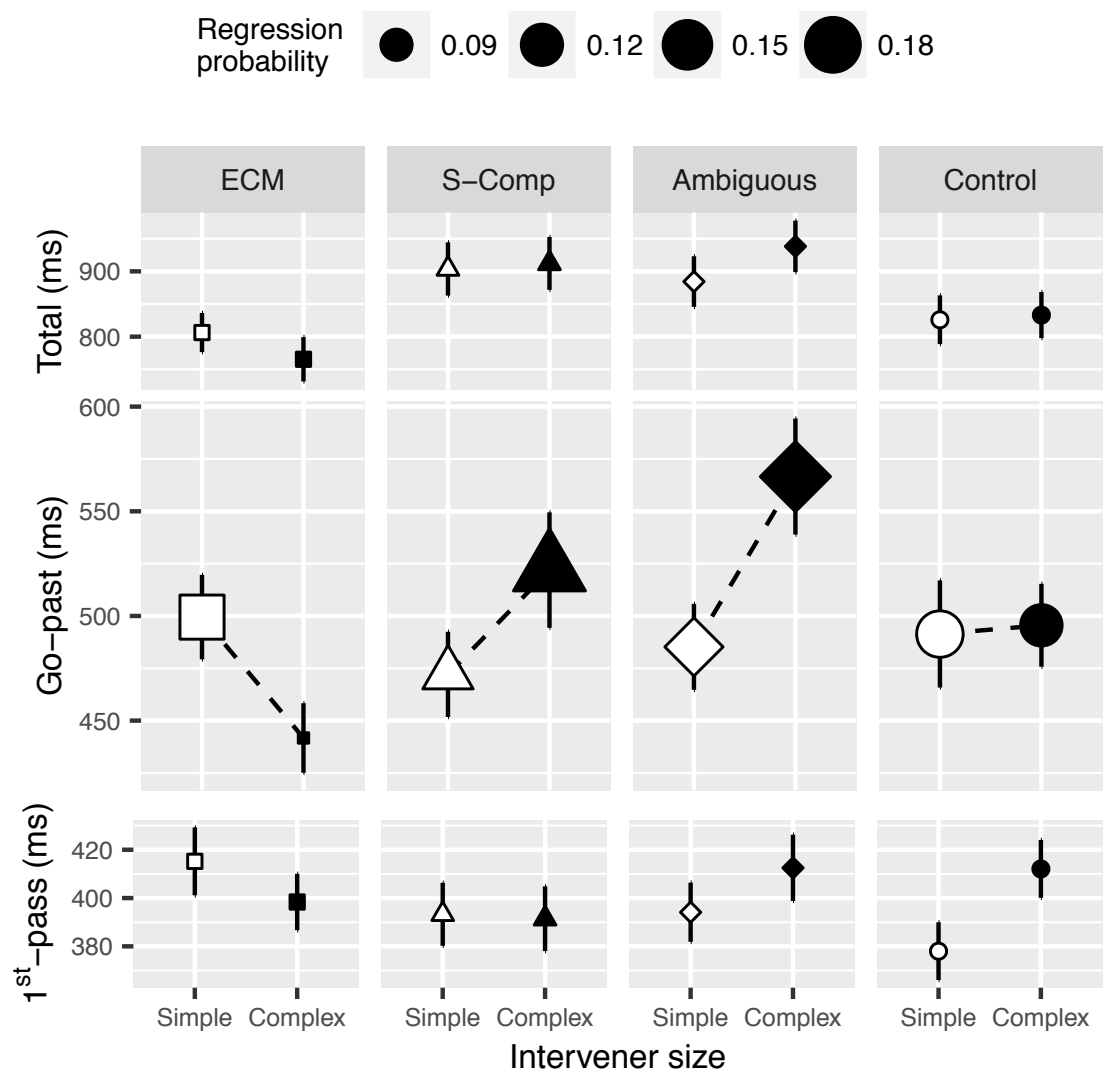

Figure 4: Experiment 3 eye-tracking measures at the critical Aux+Verb region, showing means for firstpass times (bottom), go-past times (center) and total times (top). Proportion of first-pass regressions out is reflected in the size of the symbols in the center-panel. Error bars show standard error of the mean.

S.E. $=13 \mathrm{~ms})$, go-past times $(\beta=107 \mathrm{~ms}$, S.E. $=15 \mathrm{~ms})$, and total times $(\beta=225$ ms, S.E. $=32 \mathrm{~ms}$ ). This effect persisted in the pooled comparisons, such that finite S-complement conditions were reliably slower than ECM conditions in first-pass times $(\beta=47 \mathrm{~ms}$, S.E. $=8 \mathrm{~ms})$, go-past times $(\beta=70 \mathrm{~ms}$, S.E. $=11 \mathrm{~ms})$, and total times ( $\beta=172 \mathrm{~ms}$, S.E. $=24 \mathrm{~ms})$. Additionally, SPEC-т $($ ECM+S-complements) intervener conditions were significantly slower than object control conditions in first-pass times $(\beta=26 \mathrm{~ms}$, S.E. $=10 \mathrm{~ms})$, go-past times $(\beta=38 \mathrm{~ms}$, S.E. $=11 \mathrm{~ms})$, and total times $(\beta=120 \mathrm{~ms}$, S.E. $=26 \mathrm{~ms})$. There were no differences at the relativizing region in 
proportion of regressions out.

\section{R4: Intervener region}

Unsurprisingly, the additional length for complex interveners was significant at the embedded subject/controller region in all measures. Complex interveners were significantly slower than simple interveners in first-pass times $(\beta=608 \mathrm{~ms}$, S.E. $=$ $42 \mathrm{~ms})$, go-past times $(\beta=893 \mathrm{~ms}$, S.E. $=60 \mathrm{~ms})$, total times $(\beta=1309 \mathrm{~ms}$, S.E. $=$ $88 \mathrm{~ms}$ ), and led to significantly more regressions out $(\beta=.34$, S.E. $=.16, \mathrm{z}=2.09$ ). Additionally, SPEC-T intervener conditions showed reliably more regressions out than object control conditions $(\beta=.2$, S.E. $=.08)$. Total times also showed significant effects of ambiguity in the finite-S-complement conditions, reflected in slower total times for ambiguous $\mathbf{S}$-complements compared to unambiguous $\mathrm{S}$-complements $(\beta=$ $89 \mathrm{~ms}$, S.E. $=33 \mathrm{~ms})$.

\section{R5-6: Embedded verb $\mathcal{E}$ pre-critical region}

The results at the embedded verb region paralleled the effects at the critical region, with additional effects of ambiguity. Complex interveners led to significantly faster total times than simple interveners $(\beta=-70 \mathrm{~ms}$, S.E. $=35 \mathrm{~ms})$. Within the $\mathrm{S}$-complement conditions, ambiguous conditions showed reliably slower total times than unambiguous conditions $(\beta=69 \mathrm{~ms}$, S.E. $=23 \mathrm{~ms})$. There was also an interaction of complexity and structure for the finite S-complement conditions in go-past times, such that ambiguous S-complement conditions with a complex intervener were reliably slower than unambiguous S-complements with complex interveners $(\beta=86 \mathrm{~ms}$, S.E. $=36 \mathrm{~ms})$. ECM conditions were reliably slower than S-complement conditions in first-pass times $(\beta=51 \mathrm{~ms}$, S.E. $=12 \mathrm{~ms})$ and go-past times $(\beta=54 \mathrm{~ms}$, S.E. $=17 \mathrm{~ms})$. Additionally, and similar to the critical region, analysis of go-past times revealed an interaction of intervener complexity and structure, reflecting a slowdown for complex interveners that was attenuated in the ECM conditions compared to S-complement conditions ( $\beta=-72$ $\mathrm{ms}$, S.E. $=27)$. SPEC-T intervener conditions were significantly slower than object control conditions in first pass times $(\beta=50 \mathrm{~ms}$, S.E. $=9 \mathrm{~ms})$, go-past times $(\beta=60 \mathrm{~ms}$, S.E. $=17 \mathrm{~ms})$, and total times $(\beta=116 \mathrm{~ms}$, S.E. $=24 \mathrm{~ms})$. There were no significant 
effects for experimental factors in the proportion of regressions out.

At the embedded object and prepositional modifier region, there were significant effects of both complexity and structure. Total times for complex interveners were reliably faster than simple intervener conditions $(\beta=-126 \mathrm{~ms}$, S.E. $=50 \mathrm{~ms})$. Within the S-complement conditions, go-past times for ambiguous S-complement conditions were reliably slower than their ambiguous counterparts $(\beta=63 \mathrm{~ms}$, S.E. $=22)$. Scomplement conditions were significantly slower than ECM conditions in go-past times $(\beta=41 \mathrm{~ms}$, S.E. $=16 \mathrm{~ms})$, total times $(\beta=132 \mathrm{~ms}$, S.E. $=26 \mathrm{~ms})$, and showed a significantly greater proportion of regressions out $(\beta=.29$, S.E. $=.09)$. First-pass times for object control conditions were significantly slower overall than spec-T conditions $(\beta=31 \mathrm{~ms}$, S.E. $=14 \mathrm{~ms})$.

\section{Discussion}

Overall, the eye-tracking results of Experiment 3 were consistent with the previous experiments' findings of interference at the matrix verb. Complex interveners led to increased difficulty at the matrix verb, but this difficulty was attenuated in Object Control sentences and reversed in ECM conditions. The results of Experiment 3 also provide evidence that the interaction of complexity and structural similarity was not due to local ambiguities in the ECM conditions.

At the critical region, S-complement conditions were more difficult when the intervening subject was a noun-noun compound, reflected as a greater proportion of regressions out and slower go-past times. This is consistent with the complexity effect of Experiments $1 \& 2$, which also used (unambiguous) S-complement conditions. However, in contrast to Experiment 2, there was no corresponding complexity effect for Object Control conditions. Instead, the eye-tracking results of the current experiment for Object Control structures indicated no effect of complexity in either go-past times or regressions out, suggesting that comprehenders are robust to interference effects in these configurations. Similarly, whereas the effect of complexity for ECM interveners was attenuated in Experiment 2, in the current experiment complex ECM sentences showed faster go-past times and fewer regressions out than simple intervener ECM sentences. 
The differences between Experiments 2 and 3 in both the presence and and form of the interference effect for accusative interveners might reflect the more natural experimental setting for eye-tracking. The facilitation for ECM sentences was reflected in the later measures of go-past times and, relatedly, regressions out. If we assume that regressions out reflect re-analysis, then this suggests that something about complex interveners reduces the need for re-analysis in the ECM sentences. However, since the moving-window display of Experiment 2 precludes any regressions to earlier constituents, then the self-paced reading task would be insensitive to an effect driven by relatively more regressions out in the simple intervener conditions. For Object Control structures, Experiment 3 used a smaller set of Object Control verbs, which were also selected to be relatively more frequent. This may have reduced by-item variability, and reduced any difficulty for integrating the relatively low-frequency Object Control structures. It is somewhat surprising, though, that any frequency effects would show up at the matrix verb, and not at the Object Control verb itself. In any case, we think that there are sufficient reasons to be wary of drawing conclusions from the Object Control results of Experiment 2, and that the results of Experiment 3 are more representative.

Taken together, the consistent patterns of difficulty for complex subjects (not objects) observed in Experiments 1 and 3, in conjunction with the modulation of this effect by the interaction with structural similarity, suggest that the retrieval structure at the verb is minimally able to distinguish between structural subjects and objects, while the interference effect is further modulated by the morphosyntactic properties of the intervening subject. We return to these conclusions in the general discussion.

The results of Experiment 3 also indicate that the complexity effect for ECM conditions was not due to the presence of a local ambiguity. First, as discussed above, at the critical region ambiguous S-complement conditions patterned with their unambiguous counterparts, not the ECM conditions. This suggests that any effect of ambiguity is resolved by the time the matrix verb is encountered. Second, while ECM and ambiguous S-complement conditions were structurally ambiguous up to the embedded verb, at this region only the ECM conditions showed the facilitation effect observed at the critical region: a slowdown for complex interveners in the ambiguous S-complement conditions, but a facilitation in the ECM conditions. On the other hand, we observed a 
clear cost of ambiguity at the embedded verb, with both ambiguous conditions showing slower go-past and total times than unambiguous conditions. (ECM conditions also showed elevated first-pass times, presumably due to the presence of an additional word in the embedded verb region.) Thus, the interaction of complexity and structure appears to be a property of subject retrieval, and not a lingering effect of ambiguity.

\section{General Discussion}

The above experiments examined the nature of the information used to re-activate subject encodings at a verb by probing for difficulty in the presence of several kinds of intervening subjects. We manipulated the complexity of the intervening subject and the syntactic properties of the potentially interfering intervener. By manipulating the similarity between the matrix and embedded subjects, we used interference effects to diagnose how the retrieval cues characterize subjects.

Our results suggest that some, but not all, subjects interfere. We found that the complexity of the intervening subject matters, in that complex interveners engendered greater difficulty at the matrix verb than simple Det+Noun interveners. Furthermore, the results of Experiments 2 and 3 indicate that the effect of complexity is modulated by the degree of morphosyntactic similarity between the complex intervener and the target subject. Overall, our results indicate that the dimensions of similarity for subject retrieval are morphosyntactic, and not thematic.

\section{Structural versus thematic subjects}

The reading time results of Experiment 1 suggest that re-activation of the subject at a verb is guided by phrase-structural, and not thematic, properties. While there was a clear interference effect for complex interveners at the main verb, there was no effect for the possessor, a thematic subject. This pattern suggests that the information in the retrieval context is sufficient to distinguish between the subjects of verbs and the possessor subjects of nominal expressions.

The lack of interference from the possessor may seem surprising in light of previous studies reporting interference from semantically similar intervening subjects. For 
example, Van Dyke (2007) investigated the role of semantic cues in subject retrieval, comparing structures like those used in Van Dyke and Lewis (2003), e.g. (24b), to structurally similar sentences such as (24a) that varied the semantic similarity between the matrix and embedded subjects.

(24) The worker was surprised that...

a. the resident who said that the neighbor was dangerous...

b. the resident who said that the warehouse was dangerous... ... was complaining about the investigation.

The results of Van Dyke (2007) replicated the interference effect from overt syntactic subjects found in Van Dyke \& Lewis (2003), but also showed an interaction of semantic and syntactic similarity: interference was more acute when the intervening element was semantically similar, e.g. neighbor.

If possessors are also semantically good subjects, as in (24), why don't they interfere? Van Dyke \& McElree (2011) suggest an answer to this question based on the syntactic position of the interfering element. They sought to replicate the semantic and syntactic interference effects observed by Van Dyke (2007) using structures such as those shown in (25).

(25) a. The attorney who the judge realized had rejected the witness in the case compromised.

b. The attorney who the judge realized had rejected the evidence in the case compromised.

Interestingly, the semantic interference effect observed in the materials of Van Dyke (2007) was absent in structures like (25). Van Dyke \& McElree (2011) suggest that the difference turns on the syntactic position of the intervener: a subject in (24), and an object in (25). These patterns, in conjunction with previous findings of interference from grammatically inappropriate subject encodings (Van Dyke \& Lewis, 2003; Van Dyke, 2007), suggest that the retrieval structure at the verb is sufficient to distinguish between, but not within, core argument positions—objects don't interfere with subjects, 
but multiple subjects lead to difficulty. The more general conclusion is that structural information is prioritized above semantic information, so that syntactic cues gate interference from otherwise semantically similar constituents (see Dillon, Mishler, Sloggett \& Phillips, 2013 for similar claims in the processing of reflexive anaphors in complex subjects, and Parker, 2014 for a competing view). Our results align with these conclusions, in that we found that complex interveners lead to difficulty, but only when structurally similar to the target subject.

\section{Intervener complexity}

The most consistent finding of our experiments was that the processing at the matrix verb was more difficult when the embedded intervener was complex, either an event nominalization (Experiment 1) or a noun-noun compound (Experiments 2 and 3). We take this to be an interference effect, for two reasons. First, the reading times results of Experiment 1 indicated a slowdown for a nominalization in subject, but not object, position, despite occurring in the same span of words. Second, comprehension question accuracy in Experiment 1 was significantly lower for overt subjects compared to the control condition, which used raising predicates without overt subjects. These patterns suggest that the complexity of the intervening constituent matters, but only when the intervener is similar to the target constituent, i.e. both are subjects.

The slowdown for complex embedded subjects is similar to previous studies showing interference effects in the processing of complex subjects, where experimental materials also used embedded finite clause complements, e.g. thought, to introduce additional subjects (Gordon et al., 2001; Van Dyke \& Lewis, 2003; Van Dyke, 2007; Van Dyke \& McElree, 2011). We extend these findings to materials that do not vary in their depth of embedding.

However, why complex interveners - when matching - lead to difficulty remains an open question. Nominalizations are more complex than simple det+noun nominals in terms of thematic structure, morphology, and length. One potential explanation, consistent with these possibilities, is that the additional complexity requires further processing which results in a stronger representation of the embedded subject constituent (Hofmeister, 2011). If complex constituents are associated with stronger rep- 
resentations, then the features of the complex intervener might disrupt those encoded on the target, a form of encoding interference, e.g. feature over-writing (Nairne, 1990; Oberauer \& Kliegl, 2006) or conflicting bindings (Logačev \& Vasishth, 2012). Alternatively, complexity may modulate difficulty because attaching additional material to a head increases its availability and facilitates (mis)retrieval due to retrieval interference. The results of the experiments presented here seem to favor the retrieval interference approach. For one, the effect of complexity arose at the verb, when the subject is retrieved, and not at the immediately preceding regions. Two, the effect is modulated by the degree of similarity between the complex constituent and the target of retrieval, the matrix subject. Finally, in both Experiments 2 and 3, the encoding conditions for the intervener remained largely constant, so that the observed differences are more likely due to retrieval. Note, however, that latency measures like eye-tracking and self-paced reading cannot distinguish between the strength of an encoding in memory and the speed of its access, both of which can modulate the accuracy of retrieval (see McElree, 2006, and references cited there). Thus, additional research is required to distinguish between encoding and retrieval interference effects, using methodologies such as the Speed-Accuracy Trade-off procedure to estimate retrieval dynamics.

The complexity effects observed here are consistent with previous studies showing that complexity modulates difficulty at the retrieval site. For instance, Hofmeister (2011) showed that filler-gap sentences were sensitive to the syntactic and semantic complexity of the filler. Complex constituents, including noun-noun compounds, led to longer reading times at the head of the filler, but facilitated processing at the gap site, with no effect on intervening regions. Hofmeister concludes that these effects implicate representational strength and similarity-based interference. In particular, Hofmeister argues that complexity modulates interference because attaching additional material to a constituent requires repeatedly re-activating that constituent's head, resulting in a stronger encoding for the complex constituent, an elaboration effect. Indeed, working within a cue-driven parsing model, Lewis \& Vasishth (2005) assume that modifying a constituent requires either re-activating a predicted head or retrieving the to-bemodified constituent, strengthening the encoding (its activation levels). For example, adjectival modification re-activates the head of the modified noun. The takeaway of 
this approach is that elaboration of a constituent has the effect of increasing the associative strength of the features bound to that constituent, increasing the probability that those features will be unique, i.e. distinct. Increasing the distinctiveness of features would modulate interference by either reducing similarity at encoding, or increasing the associative match between the features of the complex constituent and the retrieval cues.

\section{Structural properties of subjecthood}

The results of Experiments $2 \& 3$ support the conclusion that subjects are identified based on their case properties, and not their syntactic position alone. Complex interveners led to greater difficulty in finite S-complement structures - longer RTs, go-past times, and more regressions out - but for ECM structures this difficulty was attenuated in self-paced reading (Experiment 2) and reversed in eye-tracking measures (Experiment 3), with faster go-past times and fewer regressions out. In Object Control structures, complex interveners led to a slowdown in Experiment 2, but had no effect in Experiment 3. These contrasting profiles might reflect task differences, such as the relatively more natural experimental task in eye-tracking, or that Experiment 3 used fewer Object Control verbs overall, with relatively higher frequency. In other words, we found strong, consistent evidence that complex subject interveners engendered interference in S-complement sentences; consistent evidence that complex interveners in ECM sentences either engender no interference or lead to facilitation; and we found inconsistent evidence for object control interveners.

The subject/object distinction is consistent with the findings of Van Dyke \& McElree (2011), and indicates that phrase-structural information in the retrieval context guides re-activation of the subject. On the other hand, the contrasting effect of complexity for S-complement and ECM structures suggests that the character of the form of the effect is sensitive to the structural properties of the intervener.

How can we account for the contrasting interference profiles for subject interveners? Assume that complexity has the effect of increasing the uniqueness of the features bound to the complex intervener, modulating the degree of cue-match between the intervener and the retrieval structure of the verb. Consistent with this view, the read- 
ing times results of Experiment 3 showed no differences between structures in simple intervener conditions - structural differences arose only for complex intervener conditions. If the features of the intervener fully match those of the retrieval target, as in S-complement structures, then complexity will strengthen the cue-match between the retrieval structure and the intervener, inhibiting subject retrieval due to cue-overload. In other words, complexity will make similarity between the intervener and target more acute. In Object Control structures, though, the intervener is an accusative object, and thus maximally dissimilar to the target nominative subject. Increasing the uniqueness of the intervener's features, then, will have no effect, since there is no competition from the intervener. Now consider ECM structures, where the intervener is similar to the target in its structural position (subject), but distinct in its case properties. In this configuration, complexity will increase the uniqueness of the accusative case feature, so a nominative case feature will become more diagnostic of the target subject. Thus, complexity has the effect of making the accusative subjects of ECM complements more distinct by highlighting their dissimilarity to the target.

\section{Diagnosing subjects}

The interactions of complexity and structural similarity indicate that abstract morphosyntactic information in the retrieval context is used to re-activate subject encodings. More specifically, the three-way contrast of structural similarity indicates that the cues provided by a finite verb identify the target subject in terms of both case and position. If only structural subjecthood mattered, then we should have observed difficulty due to interference from both S-complement and ECM interveners, which both match the target in their structural position. Similarly, if only the case properties of the target subject mattered, then a stronger case cue would have led to difficulty in Scomplement structures, as we observed, but would have made no distinction between the accusative interveners of ECM and Object Control structures, contrary to our results. In contrast to these predictions, we found that subject interveners interfere, while object interveners don't. This indicates that structural subjecthood (the position cue) is a necessary condition for interference. However, we also found that the form of this interference depends on the degree of case similarity between the intervening subject 
and the nominative target: a slowdown for the fully-matching nominative interveners of S-complement sentences, but a facilitation effect for the partially-matching accusative subjects of ECM sentences.

Is a retrieval cue for case plausible, even when case properties are not morphologically reflected, as in our materials? Fedorenko et al. (2004) examined the role of abstract and morphological case in Russian, where richer case morphology and syncretic case markers provide a means to evaluate the role of case features in retrieval, independent of their morphological realization. Using a self-paced reading methodology, a $2 \times 2$ design manipulated similarity between two case-marked NPs in structures like those schematized in (26). The embedded participle assigns case to NP1, which was either ACCUSATIVE or DATIVE, while NP2 is assigned ACcusative case by the matrix verb. Crucially, the ACC and DAT case forms are syncretic in feminine nouns, but not masculine nouns. By manipulating the gender of NP1, Fedorenko et al. (2004) varied whether NP1 and NP2 matched in morphological case, abstract case, or both.

(26) [ Participle NP1 $\left.{ }_{\text {ACC/DAT }}\right]$ NP2 $2_{\mathrm{ACC}}$ Verb NP3 $3_{\text {SUBJ }} \mathrm{PP}_{1} \mathrm{PP}_{2}$

The results of Fedorenko et al. (2004) showed a slowdown at the verb when both preceding object NPs matched in both abstract and morphological case, an interaction effect. This pattern is consistent with the results of our experiments, if we assume that in the absence of morphological case (there were no pronouns in our materials) retrieval relies on abstract case alone. Further evidence comes from Logačev \& Vasishth (2012), who showed that similarity in abstract case alone was sufficient to engender interference in the processing of German sentences.

In summary, the results of the current study replicated previous findings of interference from embedded subjects, but demonstrates this effect to be modulated by both the complexity and syntactic properties of the intervening subject. In all three experiments, the S-complement conditions patterned together, with a slowdown at the main verb when the embedded subject was complex, either an event nominalization or a noun-noun compound. In contrast, complex accusative interveners in ECM structures facilitated processing at the main verb, but had no effect on subject retrieval in Object Control sentences, where the intervener was an accusative object. Taken together, the 
patterns of interference for grammatically inappropriate subjects, but not objects, supports a retrieval cue for the syntactic position of the intervener. The modulation of this effect in S-complement and ECM sentences supports a retrieval cue for case, while the contrast between accusative subjects (ECM) and accusative objects (Object Control) argues against the view that retrieval relies on case alone.

Retrieval cues for both case and position are consistent with the grammatical requirements of English root clauses: a tensed verb or auxiliary requires a nominative subject. Assuming these cues are supplied by the verb, we expect that the interference profile would be different if the critical word for retrieval had different requirements. For example, the infinitive "to" requires its subject to not be in a tensed clause ${ }^{3}$. The experiments reported here were not designed to test this prediction, but the embedded clauses of the ECM and Object Control sentences of Experiments 2-3 provide some supporting evidence. In Experiment 2, ECM sentences showed faster processing at the embedded verb and subsequent word than S-complement sentences. Since S-complement and ECM sentences differed only in the embedded verb (tensed versus untensed, respectively) this could suggest that the cues provided by the embedded infinitive of the ECM sentences mitigate interference from the matrix nominative subject. In Experiment 3, ECM sentences were slower overall than S-complement sentences, but in contrast to the facilitation for complex interveners observed at the matrix tensed verb, there was no corresponding effect of complexity. Furthermore, the Object Control sentences of Experiment 3 showed faster processing at the embedded VP than either ECM or S-complement sentences, though in Experiment 2 this effect was presumably masked by a general slowdown throughout the embedded regions. Overall, then, the contrasting interference profiles between untensed embedded verbs and tensed matrix verbs give credence to the idea that the cues provided by the verb are based on that verb's grammatical requirements. In our materials, though, the effects at the embedded verb were potentially prone to spillover effects from processing complex interveners, and the embedded clauses were not matched for length at this region. Given these issues, we leave this as a particularly fruitful direction for future research.

\footnotetext{
${ }^{3}$ We are grateful to Julie Van Dyke for pointing this out.
} 


\section{Conclusions}

The above experiments converge with a rapidly growing body of research indicating that similarity-based interference is a crucial determinant of difficulty in the comprehension of linguistic dependencies. Interference effects are a key prediction of models utilizing content-addressable retrieval, and so the current study also provides evidence that sentence-processing is mediated by a cue-driven retrieval mechanism operating over content-addressable memory representations. The above experiments extend this research by demonstrating that interference effects in subject retrieval are driven by syntactic information provided by the retrieval context. More specifically, our results indicate that the relevant dimensions of structural similarity (for subjects) involve both structural position and case properties. At the very least, our results indicate that the retrieval cues should distinguish between (i) subjects of a verb and subjects of a nominal; (ii) syntactic subjects and syntactic objects; and (iii) nominative subjects of a finite clause and accusative subjects of a non-finite clause.

\section{Acknowledgments}

We are grateful to audiences at CUNY 2012, AMLaP 2014, LSA 2015, Sandra Chung, and Emily Pendelton. Initial versions of this manuscript benefited immensely from the comments of Julie Van Dyke and an anonymous reviewer.

Abney, S. P. (1987). The English noun phrase in its sentential aspect. Ph.D. thesis Massachusetts Institute of Technology.

Anderson, M. C., \& Neely, J. H. (1996). Interference and inhibition in memory retrieval. Memory, 22, 586.

Baayen, R. H., Davidson, D. J., \& Bates, D. M. (2008). Mixed-effects modeling with crossed random effects for subjects and items. Journal of Memory and Language, $59,390-412$.

Barr, D. J., Levy, R., Scheepers, C., \& Tily, H. J. (2013). Random effects structure for confirmatory hypothesis testing: Keep it maximal. Journal of Memory and Language, 68, 255-278. 
Bates, D., Maechler, M., Bolker, B., \& Walker, S. (2013). Ime4: Linear mixed-effects models using Eigen and S4. URL: http: //CRAN . R-project .org/package=lme4 r package version 1.0-5.

Bouchard, D. (1984). On Content of Empty Categories. Foris, Dordrecht.

Bresnan, J. (1982). The mental representation of grammatical relations volume 1 . The MIT Press.

Chomsky, N. (1970). Remarks on nominalization. In L. Jacobs, \& P. Rosenbaum (Eds.), Readings in English Transformational Grammar (pp. 184-221). Waltham, MA: Ginn \& Comany.

Chomsky, N. (1981). Lectures on government and binding. Dordrecht: Foris.

Chomsky, N. (1995). The Minimalist program volume 28. The MIT Press.

Chomsky, N., \& Lasnik, H. (1993). The theory of principles and parameters. Syntax: An international handbook of contemporary research, 1, 506-569.

Clifton, C., Staub, A., \& Rayner, K. (2007). Eye movements in reading words and sentences. Eye movements: A window on mind and brain, (pp. 341-372).

Dillon, B., Mishler, A., Sloggett, S., \& Phillips, C. (2013). Contrasting intrusion profiles for agreement and anaphora: Experimental and modeling evidence. Journal of Memory and Language, 69, 85-103.

Drenhaus, H., Saddy, D., \& Frisch, S. (2005). Processing negative polarity items: When negation comes through the backdoor. Linguistic evidence: Empirical, theoretical, and computational perspectives, (pp. 145-165).

Fedorenko, E., Babyonyshev, M., \& Gibson, E. (2004). The nature of case interference in on-line sentence processing in russian. In Proceedings of New England Linguistics Society (pp. 215-226). volume 34.

Ferreira, F., \& Clifton, C. (1986). The independence of syntactic processing. Journal of Memory and Language, 25, 348-368. 
Frazier, L., \& Rayner, K. (1982). Making and correcting errors during sentence comprehension: Eye movements in the analysis of structurally ambiguous sentences. Cognitive psychology, 14, 178-210.

Gelman, A., \& Hill, J. (2007). Data analysis using regression and multilevel/hierarchical models. Cambridge University Press.

Gordon, P. C., Hendrick, R., \& Johnson, M. (2001). Memory interference during language processing. Journal of Experimental Psychology: Learning, Memory, and Cognition, 27, 1411.

Gordon, P. C., Hendrick, R., \& Johnson, M. (2004). Effects of noun phrase type on sentence complexity. Journal of Memory and Language, 51, 97-114.

Gordon, P. C., Hendrick, R., Johnson, M., \& Lee, Y. (2006). Similarity-based interference during language comprehension: Evidence from eye tracking during reading. Journal of Experimental Psychology: Learning, Memory, and Cognition, 32, 1304.

Grimshaw, J. (1990). Argument structure.. the MIT Press.

Grodner, D., \& Gibson, E. (2005). Consequences of the serial nature of linguistic input for sentenial complexity. Cognitive Science, 29, 261-290.

Hofmeister, P. (2011). Representational complexity and memory retrieval in language comprehension. Language and cognitive processes, 26, 376-405.

Inhoff, A. W. (1984). Two stages of word processing during eye fixations in the reading of prose. Journal of Verbal Learning and Verbal Behavior, 23, 612-624.

Jaeger, T. F. (2008). Categorical data analysis: Away from anovas (transformation or not) and towards logit mixed models. Journal of Memory and Language, 59, 434446.

Jaeger, T. F., Fedorenko, E., \& Gibson, E. (2010). Anti-locality in english: Consequences for theories of sentence comprehension. Manuscript submitted for publication, . 
Just, M. A., Carpenter, P. A., \& Woolley, J. D. (1982). Paradigms and processes in reading comprehension. Journal of Experimental Psychology: General, 111, 228.

Kwon, N., \& Sturt, P. (2014). The use of control information in dependency formation: An eye-tracking study. Journal of Memory and Language, 73, 59-80.

Landau, I. (2006). Severing the distribution of pro from case. Syntax, 9, 153-170.

Levy, R., Fedorenko, E., \& Gibson, E. (2013). The syntactic complexity of russian relative clauses. Journal of Memory and Language, 69, 461-495.

Lewis, R. (1996). A theory of grammatical but unacceptable embeddings. Journal of Psycholinguistic Research, 25, 93-116.

Lewis, R. L., \& Vasishth, S. (2005). An activation-based model of sentence processing as skilled memory retrieval. Cognitive Science, 29, 375-419.

Logačev, P., \& Vasishth, S. (2012). Case matching and conflicting bindings interference. In Case, Word Order and Prominence (pp. 187-216). Springer.

Martin, R. (2001). Null case and the distribution of pro. Linguistic inquiry, 32, 141166.

McCloskey, J. (1997). Subjecthood and subject positions. In L. Haegeman (Ed.), Elements of Grammar (p. 197-235). Kluwer Academic Publishers.

McElree, B. (2006). Accessing recent events. Psychology of learning and motivation, $46,155-200$.

McElree, B., Foraker, S., \& Dyer, L. (2003). Memory structures that subserve sentence comprehension. Journal of Memory and Language, 48, 67-91.

Meseguer, E., Carreiras, M., \& Clifton, C. (2002). Overt reanalysis strategies and eye movements during the reading of mild garden path sentences. Memory $\mathcal{E}$ Cognition, $30,551-561$.

Nairne, J. S. (1990). A feature model of immediate memory. Memory E Cognition, $18,251-269$. 
Nairne, J. S. (2006). Modeling distinctiveness: Implications for general memory theory. In R. Hunt, \& J. Worthen (Eds.), Distinctiveness and memory (pp. 27-46). New York: Oxford University Press.

Oberauer, K., \& Kliegl, R. (2006). A formal model of capacity limits in working memory. Journal of Memory and Language, 55, 601-626.

Parker, D. J. (2014). The cognitive basis for encoding and navigating linguistic structure. Ph.D. thesis University of Maryland, College Park. URL: http://hdl.handle.net/1903/15768.

Pollard, C., \& Sag, I. (1994). Head-driven phrase structure grammar. University of Chicago Press.

R Core Team (2013). R: A Language and Environment for Statistical Computing. $\mathrm{R}$ Foundation for Statistical Computing Vienna, Austria. URL: http://www.R-project.org.

Rayner, K. (1977). Visual attention in reading: Eye movements reflect cognitive processes. Memory $\mathcal{E}$ Cognition, 5, 443-448.

Rayner, K., Sereno, S. C., \& Raney, G. E. (1996). Eye movement control in reading: a comparison of two types of models. Journal of Experimental Psychology: Human Perception and Performance, 22, 1188.

Roberts, R., \& Gibson, E. (2002). Individual differences in sentence memory. Journal of Psycholinguistic Research, 31, 573-598.

Staub, A. (2011). Word recognition and syntactic attachment in reading: Evidence for a staged architecture. Journal of Experimental Psychology: General, 140, 407-433.

Sturt, P., Pickering, M. J., \& Crocker, M. W. (1999). Structural change and reanalysis difficulty in language comprehension. Journal of Memory and Language, 40, 136150. 
Van Dyke, J. A. (2007). Interference effects from grammatically unavailable constituents during sentence processing. Journal of Experimental Psychology: Learning, Memory, and Cognition, 33, 407.

Van Dyke, J. A., \& Lewis, R. L. (2003). Distinguishing effects of structure and decay on attachment and repair: A cue-based parsing account of recovery from misanalyzed ambiguities. Journal of Memory and Language, 49, 285-316.

Van Dyke, J. A., \& McElree, B. (2006). Retrieval interference in sentence comprehension. Journal of Memory and Language, 55, 157-166.

Van Dyke, J. A., \& McElree, B. (2011). Cue-dependent interference in comprehension. Journal of Memory and Language, 65, 247-263.

Vasishth, S., Brüssow, S., Lewis, R. L., \& Drenhaus, H. (2008). Processing polarity: How the ungrammatical intrudes on the grammatical. Cognitive Science, 32, 685712.

Vasishth, S., \& Lewis, R. L. (2006). Argument-head distance and processing complexity: Explaining both locality and antilocality effects. Language, (pp. 767-794).

Wagers, M. W. (2008). The structure of memory meets memory for structure in linguistic cognition. Ph.D. thesis University Of Maryland, College Park.

Wagers, M. W., Lau, E. F., \& Phillips, C. (2009). Agreement attraction in comprehension: Representations and processes. Journal of Memory and Language, 61, 206-237. 


\begin{tabular}{lllllll|l|l|l}
\hline Structure & $\begin{array}{l}\text { INTERVENER } \\
\text { COMPLEXITY }\end{array}$ & $\begin{array}{l}\text { Region 2 } \\
\text { Target }\end{array}$ & $\begin{array}{l}\text { Region 3 } \\
\text { who+V(+that) }\end{array}$ & $\begin{array}{l}\text { Region 4 } \\
\text { Intervener }\end{array}$ & $\begin{array}{l}\text { Region 5 } \\
\text { Embedded V }\end{array}$ & $\begin{array}{l}\text { Region 6 } \\
\text { Pre-crit }\end{array}$ & $\begin{array}{l}\text { Region 7 } \\
\text { Critical }\end{array}$ & $\begin{array}{l}\text { Region 8 } \\
\text { Spillover }\end{array}$ \\
\hline $\begin{array}{l}\text { First pass times } \\
\text { (ms) }\end{array}$ & Simple & $428(17)$ & $473(17)$ & $407(14)$ & $571(22)$ & $894(31)$ & $415(14)$ & $564(23)$ \\
ECM & Complex & $405(14)$ & $430(16)$ & $998(40)$ & $553(21)$ & $850(30)$ & $398(12)$ & $589(26)$ \\
S-comp & Simple & $388(14)$ & $463(17)$ & $411(15)$ & $451(17)$ & $908(35)$ & $394(12)$ & $548(22)$ \\
- ambig. & Complex & $432(19)$ & $449(17)$ & $1039(42)$ & $498(19)$ & $755(31)$ & $412(14)$ & $544(23)$ \\
S-comp & Simple & $403(17)$ & $621(24)$ & $359(15)$ & $446(17)$ & $856(32)$ & $393(13)$ & $524(23)$ \\
- unambig. & Complex & $391(13)$ & $639(27)$ & $902(43)$ & $450(16)$ & $822(31)$ & $391(13)$ & $552(24)$ \\
Object Control & Simple & $388(13)$ & $446(14)$ & $403(14)$ & $429(16)$ & $920(32)$ & $378(12)$ & $567(25)$ \\
& Complex & $397(14)$ & $444(15)$ & $1012(38)$ & $394(15)$ & $895(31)$ & $412(12)$ & $577(21)$
\end{tabular}

\begin{tabular}{lllllll|l|l}
$\begin{array}{l}\text { Go-past }(m s) \\
\text { ECM }\end{array}$ & Simple & $521(25)$ & $531(20)$ & $597(31)$ & $735(32)$ & $1096(39)$ & $499(20)$ & $3922(215)$ \\
& Complex & $480(21)$ & $554(27)$ & $1463(56)$ & $688(32)$ & $993(30)$ & $442(17)$ & $4354(245)$ \\
\hline S-comp & Simple & $501(24)$ & $553(23)$ & $574(28)$ & $544(23)$ & $1199(46)$ & $485(21)$ & $4439(256)$ \\
一 ambig. & Complex & $524(24)$ & $598(27)$ & $1434(55)$ & $732(43)$ & $1213(63)$ & $567(28)$ & $4699(253)$ \\
\hline S-comp & Simple & $524(25)$ & $739(27)$ & $562(31)$ & $558(27)$ & $1098(37)$ & $472(20)$ & $4550(256)$ \\
- unambig. & Complex & $485(24)$ & $830(40)$ & $1334(50)$ & $581(35)$ & $1022(36)$ & $522(28)$ & $5013(255)$ \\
\hline Object Control & Simple & $463(20)$ & $528(21)$ & $507(23)$ & $568(30)$ & $1112(39)$ & $491(26)$ & $4029(218)$ \\
& Complex & $496(23)$ & $547(24)$ & $1425(59)$ & $517(30)$ & $1056(39)$ & $496(20)$ & $4047(228)$
\end{tabular}

\begin{tabular}{lllllll|l|l|}
$\begin{array}{l}\text { Total times }(m s) \\
\text { ECM }\end{array}$ & Simple & $1047(41)$ & $1095(44)$ & $937(39)$ & $1172(46)$ & $1673(62)$ & $806(30)$ & $910(35)$ \\
& Complex & $1084(50)$ & $1189(54)$ & $2176(85)$ & $1062(44)$ & $1534(60)$ & $765(34)$ & $1008(44)$ \\
\hline S-comp & Simple & $1087(49)$ & $1276(59)$ & $987(44)$ & $1079(48)$ & $1930(79)$ & $884(39)$ & $981(39)$ \\
- ambig. & Complex & $1136(47)$ & $1254(52)$ & $2525(96)$ & $1175(46)$ & $1916(76)$ & $938(39)$ & $982(37)$ \\
\hline S-comp & Simple & $1117(51)$ & $1697(72)$ & $914(44)$ & $994(44)$ & $1881(74)$ & $904(41)$ & $997(44)$ \\
-unambig. & Complex & $1079(49)$ & $1707(72)$ & $2162(83)$ & $938(37)$ & $1769(65)$ & $912(41)$ & $1027(45)$ \\
\hline Object Control & Simple & $1056(46)$ & $1045(39)$ & $956(40)$ & $890(41)$ & $1761(66)$ & $826(37)$ & $996(46)$ \\
& Complex & $1056(47)$ & $1108(42)$ & $2228(86)$ & $806(39)$ & $1587(59)$ & $833(35)$ & $933(34)$
\end{tabular}

\begin{tabular}{|c|c|c|c|c|c|c|c|c|}
\hline \multicolumn{9}{|c|}{ Regressions out (\%) } \\
\hline \multirow[t]{2}{*}{ ECM } & Simple & $13.8(2.6)$ & $8.9(2.1)$ & $21.9(3.1)$ & $18.7(2.9)$ & $14.7(2.6)$ & $15.3(2.7)$ & $91.1(2.1)$ \\
\hline & Complex & $10.7(2.4)$ & $16.9(2.9)$ & $29.7(3.5)$ & $12.3(2.5)$ & $12.8(2.6)$ & $6.7(1.9)$ & $91.8(2.1)$ \\
\hline S-comp & Simple & $14.4(2.7)$ & $14(2.6)$ & $23.6(3.2)$ & $17.2(2.9)$ & $21.1(3.1)$ & $13.9(2.6)$ & $93.7(1.9)$ \\
\hline —ambig. & Complex & $13.1(2.5)$ & $18.1(2.9)$ & $25.7(3.3)$ & $20.8(3.1)$ & $27.5(3.4)$ & $18.4(2.9)$ & $92.7(2)$ \\
\hline S-comp & Simple & $14.9(2.8)$ & $15.2(2.8)$ & $29.8(3.5)$ & $18.2(3)$ & $19.3(3)$ & $10.6(2.4)$ & $90.1(2.3)$ \\
\hline —unambig. & Complex & $10.1(2.4)$ & $16.1(2.9)$ & $26.7(3.5)$ & $13.8(2.7)$ & $19.3(3.1)$ & $17.1(3.1)$ & $93.7(1.9)$ \\
\hline \multirow[t]{2}{*}{ Object Control } & Simple & $9.8(2.3)$ & $11(56)$ & $16.3(2.8)$ & $16.5(2.9)$ & $15.5(2.8)$ & $14(2.7)$ & $93.1(1.9)$ \\
\hline & Complex & $13.1(2.6)$ & $12.3(2.5)$ & $23.3(3.2)$ & $14.9(2.8)$ & $14(2.6)$ & $12(2.5)$ & $87.8(2.5)$ \\
\hline
\end{tabular}

Table 7: Experiment 3 means (and standard errors) for first-pass, go-past, total times, and proportion of regressions out. Aggregated over participants/items, after removing extreme values (> $|3|$ s.d. by region and condition). 


\begin{tabular}{|c|c|c|c|c|c|c|c|c|c|c|c|c|c|c|c|}
\hline & \multicolumn{4}{|c|}{ First-pass times (ms) } & \multicolumn{3}{|c|}{ Regressions out (\%) } & \multicolumn{4}{|c|}{ Go-past times (ms) } & \multicolumn{4}{|c|}{ Total times (ms) } \\
\hline & $\beta$ & SE & $t$ & Slope & $\beta$ & se & $z$ & $\beta$ & se & $t$ & Slope & $\beta$ & se & $t$ & Slope \\
\hline \multicolumn{16}{|l|}{ Critical region } \\
\hline (Intercept) & 398 & 14 & $28.37^{*}$ & $(p, i)$ & -2.09 & 0.15 & $-13.66^{*}$ & 494 & 19 & $25.58^{*}$ & $(p, i)$ & 843 & 40 & $21.05^{*}$ & $(p, i)$ \\
\hline Complexity & 12 & 12 & 1.02 & $(p, i)$ & -0.22 & 0.2 & -1.12 & -2 & 20 & -0.11 & $(p, i)$ & -5 & 30 & -0.16 & $(p, i)$ \\
\hline S-comp v. Amb. & -5 & 6 & -0.83 & $(p, i)$ & -0.08 & 0.11 & -0.74 & -11 & 14 & -0.8 & $(p, i)$ & 1 & 19 & 0.06 & $(p, i)$ \\
\hline$\times$ Complexity & -6 & 13 & -0.46 & $(p, i)$ & 0.12 & 0.22 & 0.56 & -10 & 25 & -0.39 & $(p, i)$ & -7 & 36 & -0.19 & $(p)$ \\
\hline ECM v. Finite-S & 4 & 6 & 0.72 & $(p, i)$ & -0.22 & 0.11 & $-1.97^{*}$ & -18 & 9 & -1.97 & $(p, i)$ & -58 & 17 & $-3.35^{*}$ & $(p, i)$ \\
\hline$\times$ Complexity & -10 & 11 & -0.89 & $(p, i)$ & -0.71 & 0.22 & $-3.24^{*}$ & -62 & 23 & $-2.71^{*}$ & $(p, i)$ & -37 & 29 & -1.28 & $(p)$ \\
\hline O.Ctrl v. Spec-T & -3 & 5 & -0.54 & $(p, i)$ & 0.03 & 0.1 & 0.29 & 4 & 9 & 0.38 & $(p, i)$ & -7 & 16 & -0.44 & $(p, i)$ \\
\hline$\times$ Complexity & 15 & 10 & 1.43 & $(p, i)$ & 0.01 & 0.2 & 0.03 & -5 & 20 & -0.25 & $(p, i)$ & 9 & 31 & 0.28 & $(p)$ \\
\hline \multicolumn{16}{|l|}{ Relative pro } \\
\hline (Intercept) & 473 & 16 & $29.4^{*}$ & $(p, i)$ & -2.14 & 0.16 & $-12.99^{*}$ & 573 & 25 & $23.31^{*}$ & $(p, i)$ & 1204 & 55 & $22.06^{*}$ & $(p, i)$ \\
\hline Complexity & -10 & 16 & -0.61 & $(p, i)$ & 0.3 & 0.2 & 1.51 & 30 & 23 & 1.28 & $(p, i)$ & 47 & 41 & 1.14 & (i) \\
\hline S-comp v. Amb. & 86 & 13 & $6.52^{*}$ & $(p, i)$ & -0.01 & 0.11 & -0.05 & 107 & 15 & $7.26^{*}$ & $(p, i)$ & 225 & 32 & $7.1^{*}$ & $(p, i)$ \\
\hline$\times$ Complexity & 11 & 25 & 0.44 & $(p, i)$ & -0.1 & 0.22 & -0.45 & 28 & 34 & 0.82 & $(p, i)$ & 13 & 46 & 0.28 & - \\
\hline ECM v. Finite-S & -47 & 8 & $-5.69^{*}$ & $(p, i)$ & -0.15 & 0.1 & -1.54 & -70 & 11 & $-6.13^{*}$ & $(p, i)$ & -172 & 24 & $-7.1^{*}$ & $(p, i)$ \\
\hline$\times$ Complexity & -18 & 18 & -0.97 & $(p, i)$ & 0.29 & 0.2 & 1.45 & -19 & 27 & -0.73 & $(p, i)$ & 60 & 39 & 1.53 & - \\
\hline O.Ctrl v. Spec-T & -26 & 10 & $-2.66^{*}$ & $(p, i)$ & -0.11 & 0.1 & -1.15 & -38 & 11 & $-3.45^{*}$ & $(p, i)$ & -120 & 26 & $-4.59^{*}$ & $(p, i)$ \\
\hline$\times$ Complexity & 9 & 15 & 0.63 & $(p, i)$ & -0.19 & 0.2 & -0.98 & -21 & 22 & -0.94 & $(p, i)$ & 14 & 38 & 0.38 & - \\
\hline \multicolumn{16}{|l|}{ Intervener } \\
\hline (Intercept) & 705 & 28 & $25.54^{*}$ & $(p, i)$ & -1.37 & 0.14 & $-9.64^{*}$ & 991 & 41 & $24.1^{*}$ & $(p, i)$ & 1604 & 78 & $20.66^{*}$ & $(p, i)$ \\
\hline Complexity & 608 & 42 & $14.38^{*}$ & $(p, i)$ & 0.34 & 0.16 & $2.09^{*}$ & 893 & 60 & $14.98^{*}$ & $(p, i)$ & 1309 & 88 & $14.81^{*}$ & $(p, i)$ \\
\hline S-comp v. Amb. & -36 & 20 & -1.8 & $(p, i)$ & 0.1 & 0.09 & 1.08 & -26 & 24 & -1.06 & $(p, i)$ & -89 & 33 & $-2.68^{*}$ & $(p, i)$ \\
\hline$\times$ Complexity & -21 & 39 & -0.55 & $(p, i)$ & -0.14 & 0.18 & -0.75 & -33 & 46 & -0.71 & $(p, i)$ & -108 & 62 & -1.76 & 0 \\
\hline ECM v. Finite-S & 9 & 14 & 0.65 & $(p, i)$ & -0.02 & 0.08 & -0.3 & 28 & 22 & 1.24 & $(p, i)$ & -43 & 29 & -1.49 & $(p, i)$ \\
\hline$\times$ Complexity & -1 & 32 & -0.04 & $(p, i)$ & 0.23 & 0.16 & 1.45 & 30 & 42 & 0.73 & $(p, i)$ & -59 & 53 & -1.12 & 0 \\
\hline O.Ctrl v. Spec-T & 9 & 13 & 0.71 & $(p, i)$ & -0.2 & 0.08 & $-2.47^{*}$ & -15 & 22 & -0.66 & $(p, i)$ & -4 & 27 & -0.14 & $(p, i)$ \\
\hline$\times$ Complexity & 8 & 27 & 0.28 & $(p, i)$ & 0.13 & 0.16 & 0.82 & 48 & 42 & 1.13 & $(p, i)$ & -8 & 51 & -0.16 & 0 \\
\hline \multicolumn{16}{|l|}{ Embedded verb } \\
\hline (Intercept) & 462 & 17 & $26.9^{*}$ & $(p, i)$ & -1.71 & 0.11 & $-15.49^{*}$ & 603 & 27 & $22.59^{*}$ & $(p, i)$ & 972 & 49 & $19.89^{*}$ & $(p, i)$ \\
\hline Complexity & -13 & 15 & -0.87 & $(p, i)$ & -0.2 & 0.18 & -1.12 & -3 & 30 & -0.11 & $(p, i)$ & -70 & 35 & $-2.01^{*}$ & $(p, i)$ \\
\hline S-comp v. Amb. & -10 & 8 & -1.24 & $(p, i)$ & -0.11 & 0.1 & -1.04 & -33 & 18 & -1.78 & $(p, i)$ & -69 & 23 & $-2.97^{*}$ & $(p, i)$ \\
\hline$\times$ Complexity & -22 & 16 & -1.33 & (p) & -0.29 & 0.21 & -1.4 & -86 & 36 & $-2.37^{*}$ & (i) & -64 & 43 & -1.47 & 0 \\
\hline ECM v. Finite-S & 51 & 12 & $4.31^{*}$ & $(p, i)$ & -0.08 & 0.09 & -0.84 & 54 & 17 & $3.13^{*}$ & $(p, i)$ & 41 & 22 & 1.83 & $(p, i)$ \\
\hline$\times$ Complexity & -21 & 17 & -1.25 & (p) & -0.22 & 0.18 & -1.19 & -72 & 27 & $-2.67^{*}$ & (i) & -61 & 33 & -1.83 & 0 \\
\hline O.Ctrl v. Spec-T & -50 & 9 & $-5.76^{*}$ & $(p, i)$ & -0.02 & 0.09 & -0.28 & -60 & 17 & $-3.62^{*}$ & $(p, i)$ & -116 & 24 & $-4.87^{*}$ & $(p, i)$ \\
\hline$\times$ Complexity & -16 & 14 & -1.13 & (p) & 0.07 & 0.18 & 0.42 & -39 & 27 & -1.48 & (i) & -20 & 30 & -0.67 & 0 \\
\hline \multicolumn{16}{|l|}{ Pre-critical } \\
\hline (Intercept) & 886 & 34 & $26.2^{*}$ & $(p, i)$ & $57-1.77$ & 0.13 & $-13.65^{*}$ & 1090 & 44 & $24.54^{*}$ & $(p, i)$ & 1716 & 81 & $21.1^{*}$ & $(p, i)$ \\
\hline Complexity & -43 & 28 & -1.55 & $(p, i)$ & -0.06 & 0.18 & -0.32 & -54 & 36 & -1.49 & $(p, i)$ & -126 & 50 & $-2.52^{*}$ & $(p, i)$ \\
\hline S-comp v. Amb. & 8 & 20 & 0.39 & $(p, i)$ & -0.15 & 0.1 & -1.52 & -63 & 22 & $-2.87^{*}$ & $(p, i)$ & -29 & 38 & -0.77 & $(p, i)$ \\
\hline$\times$ Complexity & 57 & 34 & 1.68 & $(p, i)$ & -0.18 & 0.19 & -0.96 & -31 & 50 & -0.63 & $(p, i)$ & -27 & 71 & -0.38 & $(p, i)$ \\
\hline ECM v. Finite-S & 19 & 15 & 1.24 & $(p, i)$ & -0.29 & 0.09 & $-3.15^{*}$ & -41 & 16 & $-2.57^{*}$ & $(p, i)$ & -132 & 26 & $-5.11^{*}$ & $(p, i)$ \\
\hline$\times$ Complexity & 20 & 26 & 0.78 & $(p, i)$ & -0.17 & 0.18 & -0.95 & -41 & 35 & -1.16 & $(p, i)$ & -43 & 52 & -0.83 & $(p, i)$ \\
\hline O.Ctrl v. Spec-T & 31 & 14 & $2.22^{*}$ & $(p, i)$ & -0.1 & 0.09 & -1.13 & 6 & 17 & 0.32 & $(p, i)$ & -26 & 27 & -0.96 & $(p, i)$ \\
\hline
\end{tabular}




\section{Appendix A. Experimental materials}

\section{Appendix A.1. Experiment 1}

We list only the poss:Yes and INTERVENER:LARGE conditions alongside the control sentence. The remaining 3 conditions can be formed by dropping the possessor and swapping the embedded nominalization subject with its object.

(1) a. Fortuitously, the villager who alleged that the priest's completion of the temple inspired the legend was found in the mountains.

b. Fortuitously, the villager who seems to have seriously investigated the legendary construction of the temple was found in the mountains.

(2) a. Posthumously, the scientist who said that the student's solution to the problem proved the theorem was recognized in a ceremony.

b. Posthumously, the scientist who was alleged to have accidentally solved the famously difficult math problem was recognized in a ceremony.

(3) a. Curiously, the farmer who claimed that the soldiers' destruction of the village prompted the rebellion was mentioned in classified documents.

b. Curiously, the farmer who appears to have recorded the brutal destruction of the enemy village was mentioned in classified documents.

(4) a. Sadly, the mayor who thought that the farmer's growth of the crops supported the market was removed in the election.

b. Sadly, the mayor who was reported to strongly support the local growth of the crops was defeated in the election.

(5) a. Hurriedly, the banker who declared that the committee's rejection of the bailout caused public outcry had come from the capitol.

b. Hurriedly, the banker who is likely to have hated the public rejection of the bailout had come from the capitol.

(6) a. Surprisingly, the critic who complained that the film's adaptation of the story contradicted the book was ignored by the fans. 
b. Surprisingly, the critic who failed to wholeheartedly enjoy the recent adaptation of the classic story was ignored by the fans.

(7) a. Improbably, the senator who proposed that the country's commemoration of the strike celebrate the workers had persevered in the debate.

b. Improbably, the senator who tended to support the official commemoration of the big labor strike had persevered in the debate.

(8) a. Suspiciously, the blogger who wrote that the company's donation to the candidate blocked the law was invited to the fundraiser.

b. Suspiciously, the blogger who had threatened to criticize the corporate contribution to the favored candidate was invited to the fundraiser.

(9) a. Unfortunately, the ambassador who implied that the UN's adoption of the resolution undermined the constitution was barred from the session.

b. Unfortunately, the ambassador who ought to have blocked the controversial adoption of the new resolution was barred from the session.

(10) a. Privately, the agent who found that the advisor's publication of the documents exposed the spy was praised in the report.

b. Privately, the spy who was proved to have exposed the illegal publication of the documents was praised in the report.

(11) a. Unceremoniously, the executive who testified that the accountant's modification of the records concealed the bribe was removed from the court.

b. Unceremoniously, the executive who was sure to have concealed the modification of the company records was removed from the court.

(12) a. Afterwards, the hostess who announced that the chef's preparation of the blowfish delayed the server was yelling in the kitchen.

b. Afterwards, the hostess who was fortunate to have delayed the preparation of the deadly blowfish was yelling in the kitchen.

(13) a. Yesterday, the minister who declared that the government's enforcement of the embargo legitimized the attack was shown on the news. 
b. Yesterday, the minister who is liable to have ordered the ruthless enforcement of the embargo was shown on the news.

(14) a. Belatedly, the reporter who alleged that the dignitary's removal from the ceremony precipitated the scandal was rebuked by the editor.

b. Belatedly, the reporter who was rumored to have instigated the rude removal of the dignitary was rebuked by the editor.

(15) a. Grudgingly, the woman who warned that the writer's criticism of the president magnified the censorship was published by the newspaper.

b. Grudgingly, the woman who was set to continue the scathing criticism of the embattled president was published by the newspaper.

(16) a. Quietly, the curator who worried that the foundation's reduction of the collection ruined the exhibit was moving to the museum.

b. Quietly, the curator who had promised to orchestrate the reduction of the private art collection was moving to the museum.

(17) a. Unsurprisingly, the technician who testified that the the compound's mixture with the air caused the explosion was examined at the trial.

b. Unsurprisingly, the technician who was due to explain the explosive mixture of the dangerous chemical was examined at the trial.

(18) a. Luckily, the principal who denied that the student's failure of the exam caused the suspension was challenged by the parents.

b. Luckily, the principal who was about to punish the unfortunate failure of the annual exam was challenged by the board.

(19) a. Irritably, the commissioner who believed that the vigilante's interrogation of the suspect prevented the murder was stopped in the lobby.

b. Irritably, the commissioner who was supposed to prevent the brutal interrogation of the only suspect was stopped in the lobby.

(20) a. Strangely, the witness who recalled that the policeman's reaction to the speech forced the riot was absent from the rally. 
b. Strangely, the witness who was bound to have enjoyed the violent reaction of the policeman was absent from the rally.

(21) a. Unhappily, the announcer who observed that the team's domination of the game disproved the record was beaten after the game.

b. Unhappily, the announcer who was wont to ridicule the total domination of the easy game was beaten after the game.

(22) a. Technically, the investigator who agreed that the engineer's analysis of the accident supported the report was vindicated in the hearings.

b. Technically, the investigator who was certain to have supported the second analysis of the accident was vindicated in the hearings.

(23) a. Oddly, the judge who objected that the prosecutor's examination of the witness delayed the recess had died in the courtroom.

b. Oddly, the judge who was unlikely to have delayed the examination of the star witness had died in the courtroom.

(24) a. Thankfully, the professor who added that the student's contribution to the project helped the university was covered in the article.

b. Thankfully, the professor who was shown to have helped the town contribution to the project was covered in the article.

(25) a. Recently, the adventurer who discovered that the king's inscription of the tomb marked the treasure was fictionalized in the film.

b. Recently, the adventurer who was fated to discover the hidden inscription of the royal treasure was fictionalized in the film.

(26) a. Actually, the colonel who ordered that the army's commencement of the attack follow the ceasefire was condemned by the general.

b. Actually, the colonel who had to have ordered the sneak attack after the official ceasefire was condemned by the general.

(27) a. Today, the advisor who noted that the comedian's discussion of the issue mentioned the politician was hired by the campaign. 
b. Today, the advisor who happens to have closely scrutinized the public discussion of the issue was hired by the campaign.

(28) a. Predictably, the magistrate who decided that the lawyer's objection to the argument overturned the defense was appealed in the proceedings.

b. Predictably, the magistrate who was apt to overturn the strenuous objection to the hostile lawyer was appealed in the proceedings.

(29) a. Wistfully, the wizard who knew that the ceremony's coronation of the king prevented the coup was held in the tower.

b. Wistfully, the wizard who was prophesied to prevent the planned coronation of the false king was held in the tower.

(30) a. Legally, the doctor who diagnosed that the patient's rejection of the transplant aggravated the illness was responsible for the operation.

b. Legally, the doctor who had first attempted to perform the dangerous transplant on the patient was responsible for the operation.

\section{Appendix A.2. Experiment 2}

Experimental sentences for Experiment 2, listing the ECM conditions (a), the Scomplement conditions (b), and the object control conditions (c). Large intervener conditions simply replaced the embedded subject/controller in $(\mathrm{a}-\mathrm{c})$ with the nounnoun compound in (d).

(1) a. Prematurely, the dean who believed the scientist to have found the solution with the experiment was beaming at the conference.

b. Prematurely, the dean who believed that the scientist had found the solution with the experiment was beaming at the conference.

c. Prematurely, the dean who emboldened the scientist to quickly find the solution with the experiment was beaming at the conference.

d. the eccentric computer scientist

(2) a. Afterwards, the journalist who proved the politician to be bribing the judge with the donation was shouting at the jury. 
b. Afterwards, the journalist who proved that the politician was bribing the judge with the donation was shouting at the jury.

c. Afterwards, the journalist who reminded the politician to quietly bribe the judge with the donation was shouting at the jury.

d. the corrupt city politician

(3) a. Ironically, the captain who preferred the commander to be monitoring the mission from the bridge was walking on the surface.

b. Ironically, the captain who preferred that the commander obediently monitor the mission from the bridge was walking on the surface.

c. Ironically, the captain who encouraged the commander to obediently monitor the mission from the bridge was walking on the surface.

d. the cocky lieutenant commander

(4) a. Patiently, the nurse who required the doctor to generously perform the surgery at the clinic was waiting in the lobby.

b. Patiently, the nurse who required that the doctor generously perform the surgery at the clinic was waiting in the lobby.

c. Patiently, the nurse who convinced the doctor to generously perform the surgery at the clinic was waiting in the lobby.

d. the expensive hospital doctor

(5) a. Fearfully, the witness who alleged the cop to have committed the crime with the defendant was trembling after the recess.

b. Fearfully, the witness who alleged that the cop had committed the crime with the defendant was trembling after the recess.

c. Fearfully, the witness who persuaded the cop to ruthlessly commit the crime with the defendant was trembling after the recess.

d. the dirty city cop

(6) a. At first, the gambler who expected the challenger to convincingly throw the match for the bribe was smirking after the fight. 
b. At first, the gambler who expected that the challenger would throw the match for the bribe was smirking after the fight.

c. At first, the gambler who paid the challenger to convincingly throw the match for the bribe was smirking after the fight.

d. the old washout challenger

(7) a. Suspiciously, the manager who desired the teenager to hurriedly leave the store without the merchandise was watching from the office.

b. Suspiciously, the manager who desired that the teenager hurriedly leave the store without the merchandise was watching from the office.

c. Suspiciously, the manager who harassed the teenager to hurriedly leave the store without the merchandise was watching from the office.

d. the young punk teenager

(8) a. Oddly enough, the inspector who assumed the waiter to be tainting the food with the bleach was whispering in the kitchen.

b. Oddly enough, the inspector who assumed that the waiter was tainting the food with the bleach was whispering in the kitchen.

c. Oddly enough, the inspector who compelled the waiter to taint the food with the bleach was whispering in the kitchen.

d. the new drink waiter

(9) a. Last night, the official who declared the candidate to be violating the law with the contributions was talking on the television.

b. Last night, the official who declared that the candidate had violated the law with the contributions was talking on the television.

c. Last night, the official who galvanized the candidate to blatantly violate the law with the contributions was talking on the television.

d. the charismatic independent candidate

(10) a. This morning, the boy who fancied the monster to live under the bed in the dark was sleeping in the kitchen. 
b. This morning, the boy who fancied that the monster lived under the bed in the dark was sleeping in the kitchen.

c. This morning, the boy who provoked the monster to live under the bed in the dark was sleeping in the kitchen.

d. the evil octopus monster

(11) a. Angrily, the engineer who found the carpenter to be ignoring the design at the site was whispering with the foreman.

b. Angrily, the engineer who found that the carpenter had ignored the design at the site was whispering with the foreman.

c. Angrily, the engineer who moved the carpenter to willfully ignore the design at the site was whispering with the foreman.

d. the clever chief carpenter

(12) a. As expected, the umpire who judged the runner to have stolen the base before the pitch was arguing in the dugout.

b. As expected, the umpire who judged that the runner had stolen the base before the pitch was arguing in the dugout.

c. As expected, the umpire who tempted the runner to bravely steal the base before the pitch was arguing in the dugout.

d. the famous star runner

(13) a. During questioning, the detective who presumed the suspect to be telling the truth in the statement had snorted during the testimony.

b. During questioning, the detective who presumed that the suspect was telling the truth in the statement had snorted during the testimony.

c. During questioning, the detective who forced the suspect to reluctantly tell the truth in the statement had snorted during the testimony.

d. the quiet murder suspect

(14) a. Quietly, the bear who supposed the ranger to have hidden the basket in the park was waiting behind the tree. 
b. Quietly, the bear who supposed that the ranger had hidden the basket in the park was waiting behind the tree.

c. Quietly, the bear who intimidated the ranger to cautiously hide the basket in the park was waiting behind the tree.

d. the friendly forest ranger

(15) a. Alarmingly, the patient who thought the nurse to have poisoned the medicine at the hospital was missing from the cafeteria.

b. Alarmingly, the patient who thought that the nurse was poisoning the medicine at the hospital was missing from the cafeteria.

c. Alarmingly, the doctor who encouraged the patient to regularly poison the medicine at the hospital was missing from the cafeteria.

d. the odd hospital nurse

(16) a. In retrospect, the analyst who declared the spy to have sold the password at the meeting had lied at the hearing.

b. In retrospect, the analyst who declared that the spy had sold the password at the meeting had lied at the hearing.

c. In retrospect, the analyst who tormented the spy to traitorously sell the password at the meeting had lied at the hearing.

d. the alleged agency spy

(17) a. At the interview, the critic who believed the minister to be suppressing the protests with excessive force was ranting at the policy.

b. At the interview, the critic who believed that the minister was suppressing the protests with excessive force was ranting at the policy.

c. At the interview, the critic who invigorated the minister to brutally suppress the protests with excessive force was ranting at the policy.

d. the new interior minister

(18) a. Somewhat surprisingly, the executive who expected the accountant to be changing the records at the office was sleeping in the cell. 
b. Somewhat surprisingly, the executive who expected that the accountant was changing the records at the office was sleeping in the cell.

c. Somewhat surprisingly, the executive who moved the accountant to illegally change the records at the office was sleeping in the cell.

d. the sneaky chief accountant

(19) a. During the game, the athlete who preferred the coach to be calling the plays from the sidelines was shouting in the locker-room.

b. During the game, the athlete who preferred that the coach always call the plays from the sidelines was shouting in the locker-room.

c. During the game, the athlete who convinced the coach to always call the plays from the sidelines was shouting in the locker-room.

d. the reliable quarterback coach

(20) a. As a joke, the pilot who required the student to be flying the plane for the certification was struggling at the controls.

b. As a joke, the pilot who required that the student competently fly the plane for the certification was struggling at the controls.

c. As a joke, the pilot who encouraged the student to competently fly the plane for the certification was struggling at the controls.

d. the young trainee student

(21) a. Shockingly, the priest who alleged the child to have cast the curse on the village was frowning at the sentencing.

b. Shockingly, the priest who alleged that the child had cast the curse on the village was frowning at the sentencing.

c. Shockingly, the priest who paid the child to sadly cast the curse on the village was frowning at the sentencing.

d. the quiet village child

(22) a. Politely, the sailor who expected the captain to promptly alter the course at the briefing was nodding at the command. 
b. Politely, the sailor who expected that the captain would alter the course at the briefing was nodding at the command.

c. Politely, the sailor who persuaded the captain to promptly alter the course at the briefing was nodding at the command.

d. the grumpy boat captain

(23) a. Impatiently, the journalist who desired the president to be investigating the incident for the government was waiting in the capitol.

b. Impatiently, the journalist who desired that the president officially investigate the incident for the government was waiting in the capitol.

c. Impatiently, the journalist who harassed the president to officially investigate the incident for the government was waiting in the capitol.

d. the embattled company president

(24) a. Ashamed, the editor who assumed the researcher to be presenting the truth in the journal had resigned at the meeting.

b. Ashamed, the editor who assumed that the researcher was presenting the truth in the journal had resigned at the meeting.

c. Ashamed, the editor who intimidated the researcher to prematurely present the truth in the journal had resigned at the meeting.

d. the respected computer researcher

(25) a. Urgently, the sheriff who declared the robber to have planned the escape before the manhunt was speaking on the television.

b. Urgently, the sheriff who declared that the robber had planned the escape before the manhunt was speaking on the television.

c. Urgently, the sheriff who forced the robber to impetuously plan the escape before the manhunt was speaking on the television.

d. the local bank robber

(26) a. Enthusiastically, the violinist who fancied the conductor to be improvising the symphony on the fly was cheering after the concert. 
b. Enthusiastically, the violinist who fancied that the conductor was improvising the symphony on the fly was cheering after the concert.

c. Enthusiastically, the violinist who inspired the conductor to brilliantly improvise the symphony on the fly was cheering after the concert.

d. the gifted orchestra conductor

(27) a. Most alarmingly, the explorer who found the monster to be prowling the ruins for the expedition was insane after the journey.

b. Most alarmingly, the explorer who found that the monster was prowling the ruins for the expedition was insane after the journey.

c. Most alarmingly, the explorer who tormented the monster to murderously prowl the ruins for the expedition was insane after the journey.

d. the ancient alien monster

(28) a. Luckily, the teacher who judged the student to have passed the exam with the report was kind with the grading.

b. Luckily, the teacher who judged that the student had passed the exam with the report was kind with the grading.

c. Luckily, the teacher who compelled the student to gracefully pass the exam with the report was kind with the grading.

d. the struggling mathematics student

(29) a. Today the villager who presumed the geologist to be examining the volcano from the rim was running to the camp.

b. Today the villager who presumed that the geologist was examining the volcano from the rim was running to the camp.

c. Today the villager who harassed the geologist to recklessly examine the volcano from the rim was running to the camp.

d. the charismatic expert geologist

(30) a. Thankfully, the historian who supposed the poet to be embellishing the story with the adventure was skeptical of the account. 
b. Thankfully, the historian who supposed that the poet had embellished the story with the adventure was skeptical of the account.

c. Thankfully, the historian who tempted the poet to mildly embellish the story with the adventure was skeptical of the account.

d. the old epic poet

(31) a. Oddly enough, the agent who knew the deputy to be chasing the killer to the mill was overjoyed with the plan.

b. Oddly enough, the agent who knew that the deputy was chasing the killer to the mill was overjoyed with the plan.

c. Oddly enough, the agent who provoked the deputy to cleverly chase the killer to the mill was overjoyed with the plan.

d. the bumbling town deputy

(32) a. A long time ago, the politician who proved the philosopher to be corrupting the youth with the manifesto was shocked at the verdict.

b. A long time ago, the politician who proved that the philosopher had corrupted the youth with the manifesto was shocked at the verdict.

c. A long time ago, the politician who emboldened the philosopher to allegedly corrupt the youth with the manifesto was shocked at the verdict.

d. the wise Greek philosopher

(33) a. Agitated, the woman who thought the conductor to be delaying the tram on the tracks was pacing in the terminal.

b. Agitated, the woman who thought that the conductor was delaying the tram on the tracks was pacing in the terminal.

c. Agitated, the woman who moved the conductor to delay the tram on the tracks was pacing in the terminal.

d. the old train conductor

(34) a. Sadly, the child who knew the man to be impersonating the character in the mall was disappointed at the party. 
b. Sadly, the child who knew that the man was impersonating the character in the mall was disappointed at the party.

c. Sadly, the child who persuaded the man to impersonate the character in the mall was disappointed at the party.

d. the man

(35) a. Of course, the blogger who proved the scientist to be falsifying the experiment at the lab was scathing at the debate.

b. Of course, the blogger who proved that the scientist had falsified the experiment at the lab was scathing at the debate.

c. Of course, the blogger who invigorated the scientist to falsify the experiment at the lab was satisfied scathing at the debate.

d. the old primate scientist

(36) a. Overcome, the psychologist who believed the veteran to be reliving the trauma in the poem was crying after the session.

b. Overcome, the psychologist who believed that the veteran was reliving the trauma in the poem was crying after the session.

c. Overcome, the psychologist who convinced the veteran to relive the trauma in the poem was crying after the session.

d. the veteran

\section{Appendix A.3. Experiment 3}

Experimental sentences for Experiment 3. Ambiguous S-complement sentences were identical the the S-complement sentences in (b) with the complementizer that omitted. Large intervener conditions were identical to the conditions in $(a-c)$ with the embedded intervener replaced by the compound given in (d).

(37) a. Prematurely, the dean who proved the scientist to have found the solution with the software was celebrating at the conference.

b. Prematurely, the dean who proved that the scientist had found the solution with the software was celebrating at the conference. 
c. Prematurely, the dean who convinced the scientist to quickly find the solution with the software was celebrating at the conference.

d. eccentric computer scientist

(38) a. Afterwards, the lawyer who proved the politician to be bribing the judge with the appointment was shouting at the jury.

b. Afterwards, the lawyer who proved that the politician was bribing the judge with the appointment was shouting at the jury.

c. Afterwards, the lawyer who persuaded the politician to quietly bribe the judge with the appointment was shouting at the jury.

d. the currupt city politician

(39) a. Meanwhile, the astronaut who believed the commander to be monitoring the mission from the bridge was walking on the surface.

b. Meanwhile, the astronaut who believed that the commander was monitoring the mission from the bridge was walking on the surface.

c. Meanwhile, the astronaut who asked the commander to vigilantly monitor the mission from the bridge was walking on the surface.

d. the cocky lieutenant commander

(40) a. Patiently, the administrator who alleged the doctor to have performed the surgery at the clinic was waiting in the lobby.

b. Patiently, the administrator who alleged that the doctor had performed the surgery at the clinic was waiting in the lobby.

c. Patiently, the administrator who urged the doctor to perform the surgery at the clinic was waiting in the lobby.

d. the expensive hospital doctor

(41) a. Fearfully, the informant who alleged the cop to have planned the crime alongside the defendant was trembling after the acquittal.

b. Fearfully, the informant who alleged that the cop had planned the crime alongside the defendant was trembling after the acquittal. 
c. Fearfully, the informant who persuaded the cop to plan the crime alongside the defendant was trembling after the acquittal.

d. the dirty city cop

(42) a. At first, the bookie who expected the fighter to throw the match for the bribe was smirking after the bout.

b. At first, the bookie who expected that the fighter would throw the match for the bribe was smirking after the bout.

c. At first, the bookie who hired the fighter to throw the match for the bribe was smirking after the bout.

d. the old champion fighter

(43) a. Anxiously, the manager who expected the teenager to leave the store without the merchandise was watching from the office.

b. Anxiously, the manager who expected that the teenager was leaving the store without the merchandise was watching from the office.

c. Anxiously, the manager who forced the teenager to leave the store without the merchandise was watching from the office.

d. the suspicious punk teenager

(44) a. Suspiciously, the inspector who assumed the chef to be washing the food with the pesticide was whispering in the kitchen.

b. Suspiciously, the inspector who assumed that the chef was washing the food with the pesticide was whispering in the kitchen.

c. Suspiciously, the inspector who advised the chef to wash the food with the pesticide was whispering in the kitchen.

d. the new appetizer chef

(45) a. Last night, the candidate who declared the businessman to have broken the law with the contributions was talking on the television.

b. Last night, the candidate who declared that the businessman had broken the law with the contributions was talking on the television. 
c. Last night, the candidate who asked the businessman to break the law with the contributions was talking on the television.

d. the charismatic celebrity businessman

(46) a. This morning, the child who imagined the monster to be inhabiting the closet in the dark was sleeping in the kitchen.

b. This morning, the child who imagined that the monster was inhabiting the closet in the dark was sleeping in the kitchen.

c. This morning, the child who forced the monster to inhabit the closet in the dark was sleeping in the kitchen.

d. the slimy octopus monster

(47) a. Angrily, the engineer who found the carpenter to be ignoring the schematic at the site had argued with the foreman.

b. Angrily, the engineer who found that the carpenter was ignoring the schematic at the site had argued with the foreman.

c. Angrily, the engineer who urged the carpenter to ignore the schematic at the site had argued with the foreman.

d. the clever chief carpenter

(48) a. As expected, the coach who believed the player to have stolen the base before the pitch was arguing with the umpire.

b. As expected, the coach who believed that the player had stolen the base before the pitch was arguing with the umpire.

c. As expected, the coach who advised the player to steal the base before the pitch was arguing with the umpire.

d. the famous star player

(49) a. During questioning, the detective who proved the suspect to be telling the truth in the statement had snorted at the story.

b. During questioning, the detective who proved that the suspect was telling the truth in the statement had snorted at the story. 
c. During questioning, the detective who paid the suspect to tell the truth in the statement had snorted at the story.

d. the quiet murder suspect

(50) a. Quietly, the bear who imagined the ranger to have hidden the basket in the park was lurking behind the tree.

b. Quietly, the bear who imagined that the ranger had hidden the basket in the park was lurking behind the tree.

c. Quietly, the bear who convinced the ranger to hide the basket in the park was lurking behind the tree.

d. the friendly forest ranger

(51) a. Alarmingly, the patient who declared the nurse to have concealed the medicine in the food was missing from the cafeteria.

b. Alarmingly, the patient who declared that the nurse had concealed the medicine in the food was missing from the cafeteria.

c. Alarmingly, the patient who forced the nurse to conceal the medicine in the food was missing from the cafeteria.

d. the old hospital nurse

(52) a. In retrospect, the spy who declared the analyst to have sold the password at the meeting was lying at the hearing.

b. In retrospect, the spy who declared that the analyst had sold the password at the meeting was lying at the hearing.

c. In retrospect, the spy who hired the analyst to sell the password at the meeting was lying at the hearing.

d. the trusted government analyst

(53) a. In the interview, the critic who believed the minister to be suppressing the protests with excessive force was ranting at the policy.

b. In the interview, the critic who believed that the minister was suppressing the protests with excessive force was ranting at the policy. 
c. In the interview, the critic who persuaded the minister to suppress the protests with excessive force was ranting at the policy.

d. the new interior minister

(54) a. Surprisingly, the executive who expected the accountant to have changed the records before the inquiry was confessing to the regulators.

b. Surprisingly, the executive who expected that the accountant had changed the records before the inquiry was confessing to the regulators.

c. Surprisingly, the executive who hired the accountant to change the records before the inquiry was confessing to the regulators.

d. the sneaky investment accountant

(55) a. During the game, the athlete who assumed the coach to have called the play from the sidelines was shouting in the locker-room.

b. During the game, the athlete who assumed that the coach had called the play from the sidelines was shouting in the locker-room.

c. During the game, the athlete who convinced the coach to call the play from the sidelines was shouting in the locker-room.

d. the reliable quarterback

(56) a. As a joke, the pilot who alleged the student to have flown the plane in the storm was struggling at the controls.

b. As a joke, the pilot who alleged that the student had flown the plane in the storm was struggling at the controls.

c. As a joke, the pilot who paid the student to fly the plane in the storm was struggling at the controls.

d. the young trainee student

(57) a. Shockingly, the elder who declared the child to be cursing the village with the spell had fled from the reaction.

b. Shockingly, the elder who declared that the child was cursing the village with the spell had fled from the reaction. 
c. Shockingly, the elder who advised the child to curse the village with the spell had fled from the reaction.

d. the shunned local child

(58) a. Politely, the sailor who expected the captain to dump the cargo at the border was ready for the command.

b. Politely, the sailor who expected that the captain would dump the cargo at the border was ready for the command.

c. Politely, the sailor who persuaded the captain to dump the cargo at the border was ready for the command.

d. the grumpy boat captain

(59) a. Impatiently, the journalist who imagined the president to be investigating the incident for the votes was waiting for the announcement.

b. Impatiently, the journalist who imagined that the president was investigating the incident for the votes was waiting for the announcement.

c. Impatiently, the journalist who asked the president to investigate the incident for the votes was waiting for the announcement.

d. the prosperous company president

(60) a. Ashamed, the editor who assumed the researcher to be presenting the results as the truth had resigned at the scandal.

b. Ashamed, the editor who assumed that the researcher was presenting the results as the truth had resigned at the scandal.

c. Ashamed, the editor who forced the researcher to present the results as the truth had resigned at the scandal.

d. the popular primate researcher

(61) a. Urgently, the sheriff who declared the robber to have planned the escape before the manhunt was speaking on the television.

b. Urgently, the sheriff who declared that the robber had planned the escape before the manhunt was speaking on the television. 
c. Urgently, the sheriff who forced the robber to plan the escape before the manhunt was speaking on the television.

d. the local bank robber

(62) a. Enthusiastically, the violinist who assumed the conductor to be improvising the symphony on the fly was cheering after the concert.

b. Enthusiastically, the violinist who assumed that the conductor was improvising the symphony on the fly was cheering after the concert.

c. Enthusiastically, the violinist who convinced the conductor to improvise the symphony on the fly was cheering after the concert.

d. the gifted orchestra conductor

(63) a. Most alarmingly, the explorer who found the monster to be prowling the ruins for the expedition was insane after the journey.

b. Most alarmingly, the explorer who found that the monster was prowling the ruins for the expedition was insane after the journey.

c. Most alarmingly, the explorer who persuaded the monster to prowl the ruins for the expedition was insane after the journey.

d. the ancient alien monster

(64) a. Luckily, the teacher who found the student to have fudged the answers in the report was kind with the grading.

b. Luckily, the teacher who found that the student had fudged the answers in the report was kind with the grading.

c. Luckily, the teacher who paid the student to fudge the answers in the report was kind with the grading.

d. the confused mathematics student

(65) a. Today, the guide who expected the geologist to be examining the volcano from the rim was running to the camp.

b. Today, the guide who expected that the geologist was examining the volcano from the rim was running to the camp. 
c. Today, the guide who hired the geologist to examine the volcano from the rim was running to the camp.

d. the charismatic expert geologist

(66) a. Thankfully, the historian who imagined the soldier to have embellished the story with the heroics was skeptical of the details.

b. Thankfully, the historian who imagined that the soldier had embellished the story with the heroics was skeptical of the details.

c. Thankfully, the historian who paid the soldier to embellish the story with the heroics was skeptical of the details.

d. the old veteran soldier

(67) a. Long ago, the politician who proved the philosopher to have corrupted the youth with the discussion was frustrated with the result.

b. Long ago, the politician who proved that the philosopher had corrupted the youth with the discussion was frustrated with the result.

c. Long ago, the politician who asked the philosopher to corrupt the youth with the discussion was frustrated with the result.

d. the wise Greek philosopher

(68) a. Agitated, the woman who imagined the conductor to have delayed the train in the morning was pacing on the platform.

b. Agitated, the woman who imagined that the conductor had delayed the train in the morning was pacing on the platform.

c. Agitated, the woman who urged the conductor to delay the train in the morning was pacing on the platform.

d. the old train conductor

(69) a. Sadly, the mechanic who assumed the salesman to have inflated the price with the estimate was disappointed at the sale.

b. Sadly, the mechanic who assumed that the salesman had inflated the price with the estimate was disappointed at the sale. 
c. Sadly, the mechanic who asked the salesman to inflate the price with the estimate was disappointed at the sale.

d. the reliable car salesman

(70) a. Yesterday, the taxidermist who proved the hunter to have faked the discovery with the footprint was scathing in the report.

b. Yesterday, the taxidermist who proved that the hunter had faked the discovery with the footprint was scathing in the report.

c. Yesterday, the taxidermist who hired the hunter to fake the discovery with the footprint was scathing in the report.

d. the reclusive animal hunter

(71) a. Overcome, the psychologist who believed the veteran to be reliving the trauma with the diorama was crying after the session.

b. Overcome, the psychologist who believed that the veteran was reliving the trauma with the diorama was crying after the session.

c. Overcome, the psychologist who convinced the veteran to relive the trauma with the diorama was crying after the session.

d. the active combat veteran

(72) a. Unsurprisingly, the smuggler who alleged the merchant to have delivered the contraband with the shipment was angry at the delay.

b. Unsurprisingly, the smuggler who alleged that the merchant had delivered the contraband with the shipment was angry at the delay.

c. Unsurprisingly, the smuggler who paid the merchant to deliver the contraband with the shipment was angry at the delay.

d. the smelly antiques merchant

(73) a. Ashamed, the artist who found the critic to have altered the review for the publicity was hiding from the press.

b. Ashamed, the artist who found that the critic had altered the review for the publicity was hiding from the press. 
c. Ashamed, the artist who advised the critic to alter the review for the publicity was hiding from the press.

d. the respected sculpture critic

(74) a. Actually, the actor who alleged the director to be sacrificing the story for the effects had raged at the script.

b. Actually, the actor who alleged that the director was sacrificing the story for the effects had raged at the script.

c. Actually, the actor who urged the director to sacrifice the story for the effects had raged at the script.

d. the action movie director

(75) a. That night, the bandit who believed the traveller to be carrying the gold in the wagon was waiting at the crossroads.

b. That night, the bandit who believed that the traveller was carrying the gold in the wagon was waiting at the crossroads.

c. That night, the bandit who advised the traveller to carry the gold in the wagon was waiting at the crossroads.

d. the weary merchant traveller

(76) a. Indignantly, the hobbyist who found the judge to have sabotaged the entry before the competition was protesting at the awards.

b. Indignantly, the hobbyist who found that the judge had sabotaged the entry before the competition was protesting at the awards.

c. Indignantly, the hobbyist who urged the judge to sabotage the entry before the competition was protesting at the awards.

d. the new model judge 